\title{
ADDITIONAL STRESS IN SOIL EMBANKMENTS SUBJECTED TO A NEW PRESTRESSED REINFORCEMENT DEVICE
}

\author{
Qishu ZHANG ${ }^{\circledR 1}$, Wuming LENG $^{1,2}$, Fang XU®1, 2*, Qi YANG®1, ${ }^{1,}$, Xi AI ${ }^{1}$ \\ ${ }^{1}$ School of Civil Engineering, Central South University, Changsha 410075, China \\ ${ }^{2}$ National Engineering Laboratory for High Speed Railway Construction, Changsha 410075, China
}

Received 20 February 2019; accepted 23 April 2019

\begin{abstract}
Theoretical solutions were derived to calculate the additional stress/prestress in a newly-developed prestressed embankment (PE), and the diffusion characteristics of the prestress in a PE with a lateral pressure plate (LPP) having width of $0.9 \mathrm{~m}$ were clarified using the theoretical solutions and a 3D finite element analysis. The results show that (1) the application of the theoretical solutions requires the net spacing between the LPP and the embankment shoulder is greater than the LPP width; (2) the maximum prestress appears in the upper part of the loading area of a LPP, and the maximum and minimum prestresses present an order of magnitude difference at the shallow depth, but the difference attenuates and the prestress gradually tends to be uniform with increasing depth; (3) the prestress propagates to the core zones that mainly bear the train loads with certain peak stress diffusion angles, and the values for the analyzed case are $50^{\circ}$ and $58^{\circ}$ in the external regions of the LPP along the slope and longitudinal directions, respectively; and (4) a continuous, effective and relatively uniform prestressing protective layer with a prestress coefficient greater than 0.1 can be formed above the core zones when the LPP spacing is properly designed.
\end{abstract}

Keywords: prestressed embankment, lateral pressure plate, theoretical solution, additional stress, diffusion characteristic, plate spacing.

\section{Introduction}

High-speed transport and heavy-haul freight have become an important developing direction of the railway systems in many countries. Subgrade is an essential component supporting the track structures; hence its quality directly determines the transportation efficiency, operation cost and safety of a railway line. Whereas, because of the increase in train speed, axle load and train formation density, embankment problems such as bearing failure, excessive deformation, lateral spread of embankment shoulders/ slopes and slope slip and instability impose an increasing influence on track performance and seriously affect the safety of the railway operation (Yang \& Feng, 2013; Dong, $\mathrm{Wu}, \mathrm{Li}, \&$ Chen, 2018). Moreover, poorly performing subgrade results in high rates of track geometry degradation and promotes higher rates of wear and deterioration of the rails, sleepers, fasteners and other special track-works (Li, 2018). Inadequate soil confining pressure and lack of lateral constraint on the embankment slopes are the main issues leading to these embankment problems (Thakur, Vinod, \& Indraratna, 2013; Lenart, Koseki, Miyashita, \&
Sato, 2014; Leng, Nie, \& Yang, 2016; G. Chen, T. Chen, Y. Chen, Huang, \& Liu, 2018a; W. B. Chen, Yin, Feng, Borana, \& R. P. Chen, 2018b).

In this regard, a number of conventional treatment methods, e.g., micro-piles (Dong et al., 2018), jet-grouting columns (Alonso \& Ramon, 2013), cement soil row piles (Xue, 2014), geogrids (Esmaeili, Naderi, Neyestanaki, \& Khodaverdian, 2018), geocell (Leshchinsky \& Ling, 2013), geotexiles (Fuggini, Zangani, Wosniok, Krebber, \& Weigand, 2016) and grouting (Sabermahani, Esmaeili, \& Neyestanaki, 2017) are employed for enhancing the railway embankments. However, these methods generally lead to traffic block, long construction period, environment pollution or large disturbance on the original embankment, and hence may cause enormous economic losses. Aiming at this issue, Leng et al. (2016) developed a new method to strengthen soil embankments by prestressing an embankment using a device that consists of a steel reinforcement bar and two lateral pressure plates (LPP). The new method can provide active lateral constraints on the

\footnotetext{
*Corresponding author. E-mail: fangxu@csu.edu.cn
} 
embankment slope and effectively improve the stress state of the embankment by providing an additional confining pressure for the embankment soil. A number of studies have demonstrated that increasing confining pressure can effectively improve the resistance of plastic soil deformation (Sivakumar et al., 2013; Lin, Shi, Sun, Wang, \& Cai, 2016), shear strength (Ghayoomi, Suprunenko, \& Mirshekari, 2017; Chen et al., 2018a, 2018b), bearing capacity (Li, Chen, \& Jiang, 2016; Leng, Xiao, Nie, Zhou, \& Liu, 2017), resilient modulus (Lackenby, Indraratna, McDowell, \& Christie, 2007; Thakur et al., 2013), critical dynamic stress (Li, Chen, \& Jiang, 2015; Zhang, Jiang, \& Su, 2018) and static and dynamic moduli (Li, Cheng, Jiang, \& Xiong, 2014; Leng et al., 2017) of the embankment soil. Therefore, the prestress employed in an embankment can markedly promote the embankment soil behavior, treat or prevent subgrade problems and effectively improve the service performance of a soil embankment.

It is desired to detect the strengthening performances of a prestressed embankment (PE) to ascertain its reinforcement mechanisms, particularly the distribution characteristics of the additional stress/prestress in a reinforced embankment. Prestressed anchorage techniques, e.g., prestressed anchored cables (Chen et al., 2018b; Xu, Tang, Liu, Yang, \& Luo, 2018), anchor piles (Xu, Chen, \& Deng, 2014), cable-frame systems (Deng, Zhao, \& Li, 2017), etc., have been widely applied in slope engineering, underground engineering and deep pit excavation to control the rock/soil deformation and maintain the stability of the entire supported structures (Ozhan \& Guler, 2017). Wu, Mao, Huang, Sun, and Yao (2010) developed a mechanical model to evaluate the additional stress field around endanchored structures. Guo, Mao, Ma, and Huang (2013) simplified the tray effect as a circular uniform pressure and proposed a model to calculate the additional stress induced by an anchored bolt-plate system. Du, Qin, and Tian (2016) investigated the stress redistribution subjected to a prestressed rock bolt using the FLAC 3D code. Lin, Zhang, D. Feng, Tang, and X. Feng (2017) obtained the distribution of prestress field of end-anchored bolts by large scale model tests. Besides, plenty of numerical simulations and model tests were also conducted to investigate the additional stress fields of prestressed anchored soil domains. However, as a newly-developed reinforcement method, the mechanical model of a PE is different from the objectives of existing literature.

The present study first established a mechanical model for a PE, and theoretical solutions were then derived to calculate the additional stress at any point in a PE. Secondly the diffusion characteristics of the prestress in a prestressed embankment were investigated using the theoretical solutions, and the validity and applicability of the theoretical formulas were demonstrated by a 3D finite element analysis (FEA). Finally, the effective diffusion zones subjected to single LPP were analyzed, and simple procedures were proposed to determine the required LPP spacing under the action of multi-LPPs. The research findings can provide theoretical basis and reference for the design of a PE.

\section{Compositions of a prestressed embankment}

Figure 1 presents the basic compositions of a PE. The main prestressed reinforcement device (PRD) consists of a prestressed steel bar, a protective sleeve tube, a pair of lateral pressure plates (LPPs) and a few external anchor devices. The components of a PRD can be prefabricated in a manufactory and directly assembled in the field, which is beneficial for saving construction time and engineering costs. The installation procedures of a PRD on an existing embankment include the following steps: (1) transversely drilling a borehole in the embankment at the designed position; (2) inserting a protective sleeve tube and a steel bar in the borehole; (3) anchoring each end of the steel bar with a LPP on the embankment slope; and (4) applying pretension force to the steel bar. The specific role of each component of a PRD is as follows: the protective sleeve tube prevents the steel bar from being destroyed/ corroded; the steel bar and the anchoring devices provide pretension force for the LPPs; the LPPs convert the pretension force to a surface pressure acting on the embankment slope and further transfer the pressure to the interior of

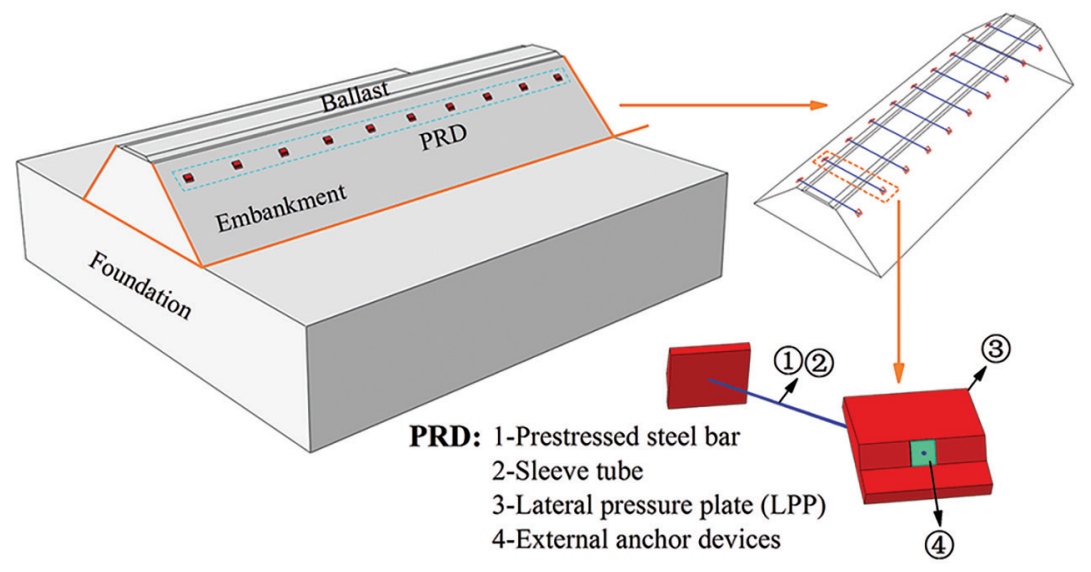

Figure 1. Schematic diagram of a prestressed embankment 
the embankment. Consequently, the PRDs provide lateral active constraints on the embankment slope, improve the stress state of the embankment soil and effectively enhance the embankment stability and the ability to resist loads and deformation.

The installation of a PRD is mainly carried out on the embankment slope, which does not need to block the traffic and can be performed during the normal operation of a railway line. Besides, thanks to the lateral constraints and additional stress provided by the PRDs, a PE can be generally constructed with a greater slope ratio compared with the corresponding unreinforced embankment. In the present study, the slope ratio of a PE is adjusted from 1:1.5 for traditional soil embankments to $1: 1$, i.e., the embankment slope angle is $45^{\circ}$. An increase in the embankment slope ratio is beneficial to reduce the embankment filling earthworks and the land occupied by the embankment base, especially for relatively high embankments. In addition, a greater slope ratio increases the normal component and reduces the tangential component of the lateral pressure provided by the LPPs, thus increasing the frictional force between the LPPs and the embankment slope surface and therefore is helpful for the LPPs to be fastened on the embankment slope.

\section{Solution of the additional stress}

Figure 2 is the cross section of a PE, where the $X, Y$ and $Z$ axes are along the slope direction, the longitudinal direction and the direction perpendicular to the slope surface, respectively. The present study mainly focuses on the distribution of the additional stress along the $Z$ direction.

The surface pressure converted from the concentrated pretension force of the prestressed steel bar $(F)$ is simplified as a horizontal uniform pressure $q . q$ is further decomposed into a uniform normal pressure perpendicular to the slope surface ( $Z$ direction, $q_{1}$ ) and a uniform tangential pressure along to the slope surface ( $X$ direction, $q_{2}$ ), as shown in Figure 3. Practically, $q, q_{1}$ and $q_{2}$ are expressed as:

$$
q=\frac{F}{L B}
$$

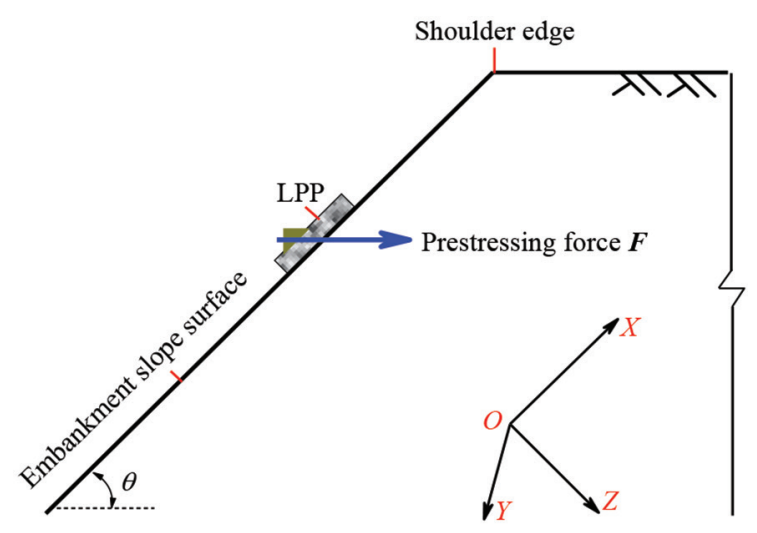

Figure 2. Cross section and calculation coordinate system of a PE

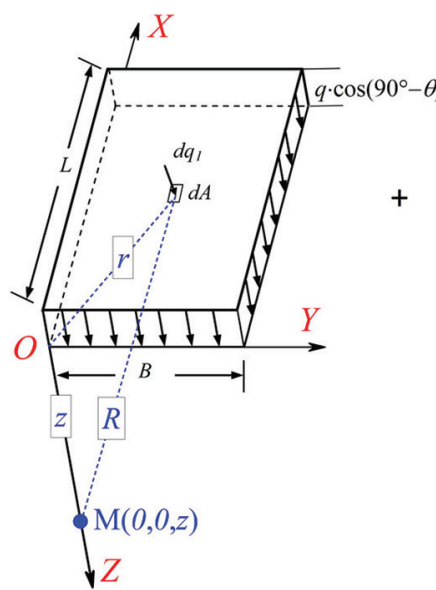

(a)

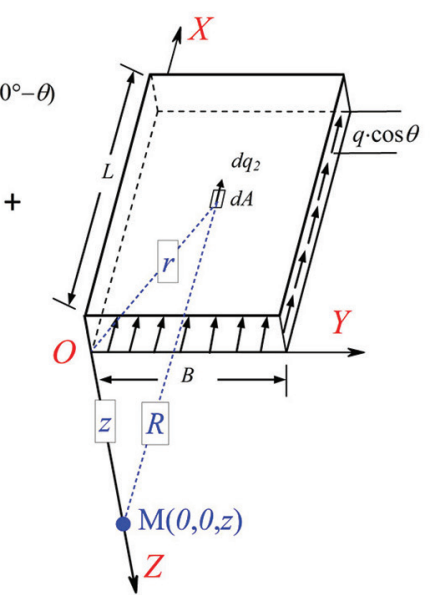

(b)
Figure 3. Pressure components at the bottom of the lateral pressure plate: (a) normal pressure component;

(b) tangential pressure component

$$
\begin{aligned}
& q_{1}=q \cdot \cos \left(90^{\circ}-\theta\right) ; \\
& q_{2}=q \cdot \cos \theta,
\end{aligned}
$$

where $L$ and $B$ are the length and width of a LPP, respectively; and $\theta$ is the angle of the embankment slope.

The normal and tangential loads applied on an arbitrary microelement area $(d A=d x d y)$ at the slope surface directly below the LPP bottom are expressed as $d N=q \cdot \cos \left(90^{\circ}-\theta\right) \cdot d x d y$ and $d T=q \cdot \cos \theta \cdot d x d y$, respectively. When $d A$ is sufficiently small, $d N$ and $d T$ become two perpendicular concentrated forces. Hence, the additional stresses (stress increments) at any point $(M)$ along the $Z$ direction caused by $d N$ and $d T$ can be calculated using the solutions of Boussinesq (1885) $\left(d \sigma_{Z N}\right.$, Eqn (4)) and Cerruti (1882) $\left(d \sigma_{Z T}\right.$, Eqn (5)), respectively.

$$
\begin{aligned}
& d \sigma_{Z N}=\frac{3 q \cdot \cos \left(90^{\circ}-\theta\right)}{2 \pi} \cdot \frac{z^{3}}{R^{5}} \cdot d x d y ; \\
& d \sigma_{Z T}= \pm \frac{3 q \cdot \cos \theta}{2 \pi} \cdot \frac{x z^{2}}{R^{5}} \cdot d x d y,
\end{aligned}
$$

where $R=\left(x^{2}+y^{2}+z^{2}\right)^{1 / 2}$ is the distance between the calculation point $M$ and the coordinate origin (point $O$ in Figure 3). When the point $M$ is under the upper boundary corners of a rectangular uniform tangential pressure, $d \sigma_{Z T}$ is a compression stress and the sign of Eqn (5) is positive $(+)$; conversely, $d \sigma_{Z T}$ is a tension stress and the sign is negative $(-)$.

Although $q_{1}$ and $q_{2}$ are two perpendicular loading pressures, the target stress $\left(\sigma_{Z}\right)$ caused by each of them is in the same direction (i.e., in the $Z$ direction). Consequently, the vector sum of the $\sigma_{Z N}$ and $\sigma_{Z T}$ directly equals their algebraic sum. Thus, combining Eqns (4) and (5), the total additional stress in the $Z$ direction $\left(d \sigma_{Z}\right)$ at any point can be given as:

$$
\begin{aligned}
& d \sigma_{Z}=d \sigma_{Z N}+d \sigma_{Z T}= \\
& {\left[\frac{3 q \cdot \cos \left(90^{\circ}-\theta\right)}{2 \pi} \cdot \frac{z^{3}}{R^{5}}+\left( \pm \frac{3 q \cdot \cos \theta}{2 \pi} \cdot \frac{x z^{2}}{R^{5}}\right)\right] \cdot d x d y .}
\end{aligned}
$$


The additional stress at point $M\left(\sigma_{Z N}\right)$ under the corners of a rectangular loading area, including a LPP or its sub-areas that are divided using the corner-points method, induced by the uniform normal pressure $\left(q_{1}\right)$ is obtained by integrating Eqn (4); the formulation is as:

$$
\begin{gathered}
\sigma_{Z N}=\int_{0}^{L_{i}} \int_{0}^{B_{i}} \frac{3 q \cdot \cos \left(90^{\circ}-\theta\right)}{2 \pi} \cdot \frac{z^{3}}{\left(x^{2}+y^{2}+z^{2}\right)^{\frac{5}{2}}} \cdot d x d y= \\
\frac{q \cdot \cos \left(90^{\circ}-\theta\right)}{2 \pi}\left[\arctan \frac{\frac{L_{i}}{B_{i}}}{\frac{z}{B_{i}} \sqrt{1+\left(\frac{L_{i}}{B_{i}}\right)^{2}+\left(\frac{z}{B_{i}}\right)^{2}}}+\right. \\
\left.\sqrt{1+\left(\frac{L_{i}}{B_{i}}\right)^{2}+\left(\frac{z}{B_{i}}\right)^{2}}\left(\frac{1}{\left(\frac{L_{i}}{B_{i}}\right)^{2}+\left(\frac{z}{B_{i}}\right)^{2}}+\frac{1}{1+\left(\frac{z}{B_{i}}\right)^{2}}\right)\right],
\end{gathered}
$$

where $L_{i}$ and $B_{i}$ are the lengths of the long and short edges of a rectangular loading area, respectively (i.e., $L_{i}=L$ and $B_{i}=B$, for a LPP in Figure 3(a)).

Similarly, the additional stress at point $M\left(\sigma_{Z T}\right)$ under the corners of a rectangular loading area subjected to the uniform tangential pressure $\left(q_{2}\right)$ is formulated as:

$$
\begin{gathered}
\sigma_{Z T}= \pm \int_{0}^{l_{i}} \int_{0}^{b_{i}} \frac{3 q}{2 \pi} \cdot \frac{x z^{2}}{\left(x^{2}+y^{2}+z^{2}\right)^{\frac{5}{2}}} \cdot d x d y= \pm \frac{q \cos \theta}{2 \pi} \\
{\left[\frac{\frac{l_{i}}{b_{i}}}{\sqrt{\left(\frac{l_{i}}{b_{i}}\right)^{2}+\left(\frac{z}{b_{i}}\right)^{2}}}-\frac{\frac{l_{i}}{b_{i}}\left(\frac{z}{b_{i}}\right)^{2}}{\left(1+\left(\frac{z}{b_{i}}\right)^{2} \sqrt{1+\left(\frac{l_{i}}{b_{i}}\right)^{2}+\left(\frac{z}{b_{i}}\right)^{2}}\right)}\right]}
\end{gathered}
$$

where $b_{i}$ and $l_{i}$ are the lengths of the loading area edges parallel and perpendicular to the direction of a uniform tangential pressure, respectively (i.e., $b_{i}=L$ and $l_{i}=B$ for a LPP in Figure 3(b)).

For simplicity, Eqns (7) and (8) are written as:

$$
\begin{aligned}
& \sigma_{Z N}=q \cdot D_{C N} \cdot \cos \left(90^{\circ}-\theta\right) ; \\
& \sigma_{Z T}=q \cdot D_{C T} \cdot \cos \theta,
\end{aligned}
$$

where $D_{C N}$ and $D_{C T}$ are the diffusion coefficients of additional stress/prestress subjected to the uniform normal and tangential pressures, respectively. The total diffusion coefficient of additional stress $\left(D_{C}\right)$ is therefore formulated as:

$$
D_{C}=D_{C N} \cdot \cos \left(90^{\circ}-\theta\right)+D_{C T} \cdot \cos \theta .
$$

\section{Diffusion characteristics of the additional stress}

\subsection{Additional stress directly beneath the bottom of a LPP}

\subsubsection{Distribution of $\sigma_{Z N}\left(D_{C N}\right)$}

The size of the LPP is an important design parameter. The main functions of the LPP are to constrain displacement, transform load, diffuse prestress and protect the embankment slope. If the size of a LPP is too small, it will be similar to a single anchor; thus, a local high pressure zone is likely to arise at the interface between the LPP and the embankment slope surface and therefore may result in excessive soil deformation, a large amount of prestress loss and a decrease in the anchorage efficiency. Conversely, if the LPP size is too large, it will be cumbersome, bulky and inconvenient for the construction of a PE and may increase the construction costs. The recommended size range of the LPP width is $0.6-1.2 \mathrm{~m}$; the weight of the LPP having width of $1.2 \mathrm{~m}$ can still be moved manually without using large mechanical equipment during the construction of a PE. In the present study, an intermediate size of $L \times B=0.9 \mathrm{~m} \times 0.9 \mathrm{~m}$ was adopted as a case study. The calculation points are arranged with equidistant spacing of $0.15 \mathrm{~m}$ in the $X$ and $Y$ directions, as illustrated in Figure 4, and they are numbered using A-D and 1-4 in the $X$ and $Y$ directions, respectively. According to symmetry, the minimum calculation region is reduced to $1 / 8$ of the loading area (see the shadow area in Figure 4(b)). Consequently, the calculation points for obtaining $D_{C N}$ are A1-A4, B2-B4, C3-C4 and D4 (10 points in total).

The calculated values of $D_{C N}$ with a $\theta$ value of $45^{\circ}$ are listed in Table 1, and Figure 5 presents the $D_{C N}$ versus depth $(z)$ curves at different calculation points. $D_{C N}$ approximately exponentially attenuates with increasing depth, and the attenuate rate gradually decreases. On the embankment slope surface, $D_{C N}$ presents significant differences with a minimum $D_{C N}\left(D_{C N \text {,min }}\right)$ of 0.25 at point G1 and a maximum $D_{C N}\left(D_{C N, \max }\right)$ approximate to 1.0 at point D4 (four times of $D_{C N \text {,min }}$ ). Whereas, the difference between $D_{C N \text {, min }}$ and $D_{C N, \max }$ gradually decreases and $D_{C N}$ tends to be uniform with increasing depth. Generally, a PRD induces relatively large and non-uniform additional stress near the embankment slope surface, but the addi-
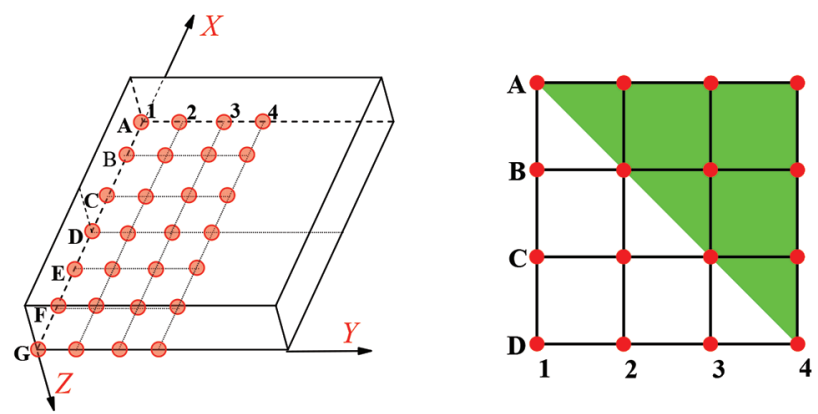

Figure 4. Position and number of typical calculation points 
Table 1. Diffusion coefficient $\left(D_{C N}\right)$ directly below the plate subjected to normal pressure $q_{1}\left(\theta=45^{\circ}\right)$

\begin{tabular}{|c|c|c|c|c|c|c|c|c|c|c|c|c|}
\hline \multirow{2}{*}{$\begin{array}{c}\text { Calculation } \\
\text { point }\end{array}$} & \multicolumn{12}{|c|}{ Depth $(z / \mathrm{m})$} \\
\hline & 0.1 & 0.2 & 0.4 & 0.6 & 0.8 & 1.0 & 1.2 & 1.4 & 1.6 & 1.8 & 2.1 & 2.4 \\
\hline $\mathrm{A} 1$ & 0.250 & 0.248 & 0.237 & 0.216 & 0.189 & 0.162 & 0.137 & 0.116 & 0.099 & 0.084 & 0.067 & 0.054 \\
\hline $\mathrm{A} 2$ & 0.480 & 0.426 & 0.341 & 0.281 & 0.231 & 0.189 & 0.155 & 0.128 & 0.107 & 0.090 & 0.071 & 0.057 \\
\hline A3 & 0.496 & 0.475 & 0.402 & 0.325 & 0.260 & 0.208 & 0.167 & 0.136 & 0.112 & 0.094 & 0.073 & 0.058 \\
\hline $\mathrm{A} 4$ & 0.498 & 0.484 & 0.420 & 0.340 & 0.270 & 0.214 & 0.172 & 0.139 & 0.114 & 0.095 & 0.074 & 0.059 \\
\hline $\mathrm{B} 2$ & 0.925 & 0.741 & 0.498 & 0.369 & 0.284 & 0.222 & 0.176 & 0.142 & 0.116 & 0.096 & 0.075 & 0.059 \\
\hline B3 & 0.954 & 0.822 & 0.587 & 0.429 & 0.321 & 0.245 & 0.190 & 0.151 & 0.122 & 0.101 & 0.077 & 0.061 \\
\hline B4 & 0.957 & 0.836 & 0.613 & 0.450 & 0.334 & 0.253 & 0.195 & 0.154 & 0.124 & 0.102 & 0.078 & 0.061 \\
\hline $\mathrm{C} 3$ & 0.986 & 0.916 & 0.693 & 0.500 & 0.363 & 0.270 & 0.206 & 0.161 & 0.129 & 0.105 & 0.080 & 0.062 \\
\hline $\mathrm{C} 4$ & 0.989 & 0.932 & 0.724 & 0.523 & 0.378 & 0.279 & 0.212 & 0.165 & 0.131 & 0.107 & 0.081 & 0.063 \\
\hline $\mathrm{D} 4$ & 0.992 & 0.948 & 0.756 & 0.549 & 0.394 & 0.289 & 0.217 & 0.168 & 0.133 & 0.108 & 0.081 & 0.063 \\
\hline
\end{tabular}

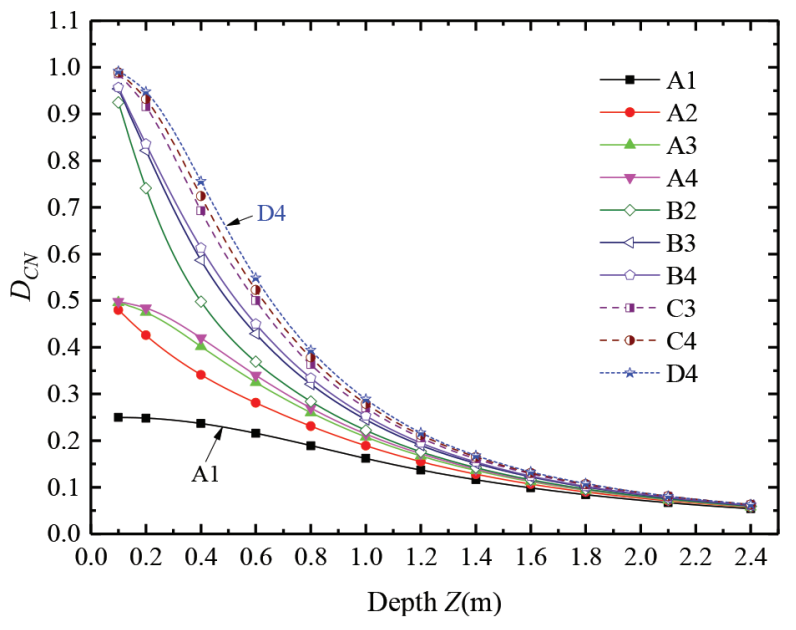

Figure 5. $D_{C N}$ versus $z$ curves at different calculation points

tional stress tends to be uniform in the regions away from the slope surface.

\subsubsection{Distribution of $\sigma_{Z T}\left(D_{C T}\right)$}

Figure 6 illustrates the stress state of the embankment soil subjected to the tangential pressure. Due to the antisymmetric effects of $q_{2}$, the soil in the upper part of the loading area is in compression, conversely, the lower part is in tension, which is in accordance with Eqns (5) and (8); the transverse centerline (see the red dash line in Figure 6) is in a zero stress state because the upper and lower parts of the tangential pressure result in opposite signs of $\sigma_{Z T}$ on this centerline. Therefore, the absolute value of the stress increases with increasing the distance from the transverse centerline. According to symmetry and anti-symmetry, the minimum calculation region is reduced to $1 / 4$ of the loading area, and the calculation points for obtaining $D_{C T}$ are A1-A4, B1-B4 and C1-C4 (12 points in total, as illustrated in Figure 4).

Table 2 lists the calculated values of $D_{C T}$ under each calculation point, and Figure 7 presents the variation curves of $D_{C T}$ (absolute values) versus $z . D_{C T}$ is overall smaller than $D_{C N}$, with a maximum value of 0.309 . In the $X$ direction, the maximum and minimum values are at the border $(X=0)$ and centerline $(X=0.45 \mathrm{~m})$ of the loading area, respectively, which is contrary to the distribution of $D_{C N}$. While in the $Y$ direction, $D_{C T}$ distributes similarly as $D_{C N}$, with the maximum and minimum values on the centerline $(Y=0.45 \mathrm{~m})$ and border $(Y=0)$ of the loading area, respectively. In addition, the $D_{C T}$ values below the border A (A1-A4) gradually decreases with increasing depth, while the $D_{C T}$ values below internal positions (B1-B4 and C1-C4) first increase to a peak value and then gradually decrease with increasing depth.

The distribution of $D_{C}$ subjected to $q$ is obtained combining $D_{C N}$ and $D_{C T}$ using Eqn (11). The values of $D_{C}$ in the left half of the loading area (the left and right halves are symmetric to the centerline) are listed in Table 3, provided the slope angle of the embankment is $45^{\circ}$.

The tangential pressure results in the largest tension stress at the lower border, which partially offsets the compression stress induced by the normal pressure; thus, the $D_{C}$ values at the lower border are smallest compared with those at other positions. In the upper part of the loading area, both the normal and tangential pressures result in

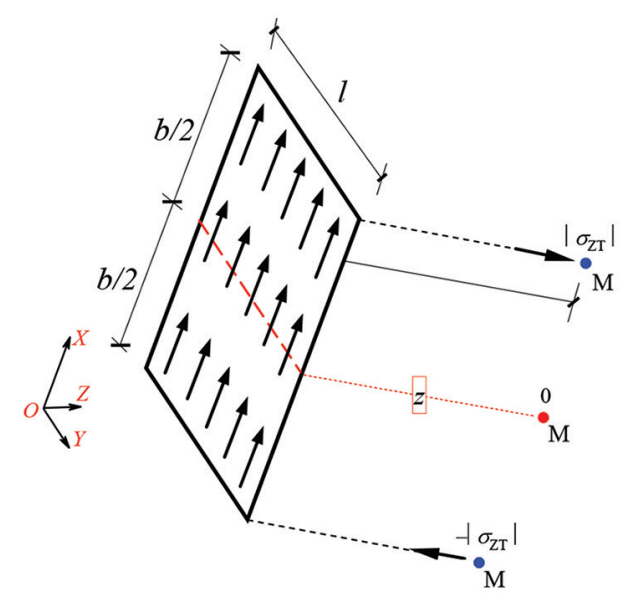

Figure 6. Additional stress $\sigma_{Z T}$ due to the action of tangential pressure $q_{2}$ 
Table 2. Diffusion coefficient $D_{C T}$ directly below the plate subjected to tangential pressure $q_{2}\left(\theta=45^{\circ}\right)$

\begin{tabular}{|c|c|c|c|c|c|c|c|c|c|c|c|c|}
\hline \multirow{2}{*}{ Points } & \multicolumn{12}{|c|}{$\operatorname{Depth}(z / \mathrm{m})$} \\
\hline & 0.1 & 0.2 & 0.4 & 0.6 & 0.8 & 1.0 & 1.2 & 1.4 & 1.6 & 1.8 & 2.1 & 2.4 \\
\hline $\mathrm{A} 1$ & 0.157 & 0.15 & 0.128 & 0.101 & 0.077 & 0.058 & 0.043 & 0.032 & 0.025 & 0.019 & 0.013 & 0.01 \\
\hline $\mathrm{A} 2$ & 0.288 & 0.243 & 0.176 & 0.128 & 0.092 & 0.067 & 0.048 & 0.036 & 0.027 & 0.021 & 0.014 & 0.01 \\
\hline $\mathrm{A} 3$ & 0.306 & 0.277 & 0.207 & 0.147 & 0.103 & 0.073 & 0.052 & 0.038 & 0.028 & 0.021 & 0.015 & 0.01 \\
\hline A4 & 0.309 & 0.284 & 0.216 & 0.153 & 0.106 & 0.075 & 0.053 & 0.039 & 0.029 & 0.022 & 0.015 & 0.01 \\
\hline B1 & 0.046 & 0.09 & 0.1 & 0.081 & 0.06 & 0.044 & 0.032 & 0.023 & 0.018 & 0.014 & 0.009 & 0.007 \\
\hline B2 & 0.076 & 0.14 & 0.138 & 0.103 & 0.073 & 0.051 & 0.036 & 0.026 & 0.019 & 0.015 & 0.01 & 0.007 \\
\hline B3 & 0.086 & 0.162 & 0.162 & 0.118 & 0.081 & 0.056 & 0.039 & 0.028 & 0.02 & 0.015 & 0.01 & 0.007 \\
\hline B4 & 0.088 & 0.167 & 0.169 & 0.124 & 0.084 & 0.058 & 0.04 & 0.028 & 0.021 & 0.015 & 0.01 & 0.007 \\
\hline $\mathrm{C} 1$ & 0.011 & 0.032 & 0.051 & 0.044 & 0.033 & 0.023 & 0.017 & 0.013 & 0.009 & 0.007 & 0.005 & 0.003 \\
\hline $\mathrm{C} 2$ & 0.017 & 0.047 & 0.069 & 0.056 & 0.04 & 0.027 & 0.019 & 0.014 & 0.01 & 0.008 & 0.005 & 0.004 \\
\hline $\mathrm{C} 3$ & 0.02 & 0.056 & 0.081 & 0.064 & 0.045 & 0.03 & 0.021 & 0.015 & 0.011 & 0.008 & 0.005 & 0.004 \\
\hline $\mathrm{C} 4$ & 0.021 & 0.058 & 0.084 & 0.067 & 0.046 & 0.031 & 0.021 & 0.015 & 0.011 & 0.008 & 0.005 & 0.004 \\
\hline $\mathrm{D}^{\#}$ & 0 & 0 & 0 & 0 & 0 & 0 & 0 & 0 & 0 & 0 & 0 & 0 \\
\hline
\end{tabular}

Table 3. Diffusion coefficient $D_{C}$ directly below the plate subjected to total pressure $q\left(\theta=45^{\circ}\right)$

\begin{tabular}{|c|c|c|c|c|c|c|c|c|c|c|c|c|}
\hline \multirow{2}{*}{ Points } & \multicolumn{12}{|c|}{$\operatorname{Depth}(z / \mathrm{m})$} \\
\hline & 0.1 & 0.2 & 0.4 & 0.6 & 0.8 & 1.0 & 1.2 & 1.4 & 1.6 & 1.8 & 2.1 & 2.4 \\
\hline A1 & 0.288 & 0.281 & 0.258 & 0.224 & 0.188 & 0.156 & 0.127 & 0.105 & 0.088 & 0.073 & 0.057 & 0.045 \\
\hline B1 & 0.372 & 0.365 & 0.312 & 0.256 & 0.206 & 0.165 & 0.132 & 0.107 & 0.088 & 0.074 & 0.057 & 0.045 \\
\hline $\mathrm{C} 1$ & 0.359 & 0.359 & 0.320 & 0.261 & 0.207 & 0.163 & 0.130 & 0.105 & 0.086 & 0.071 & 0.055 & 0.043 \\
\hline D1 & 0.352 & 0.342 & 0.297 & 0.240 & 0.191 & 0.151 & 0.122 & 0.098 & 0.081 & 0.067 & 0.052 & 0.042 \\
\hline E1 & 0.343 & 0.313 & 0.248 & 0.199 & 0.161 & 0.131 & 0.106 & 0.087 & 0.073 & 0.062 & 0.048 & 0.039 \\
\hline F1 & 0.307 & 0.238 & 0.170 & 0.141 & 0.121 & 0.103 & 0.087 & 0.074 & 0.063 & 0.054 & 0.044 & 0.035 \\
\hline G1 & 0.066 & 0.069 & 0.077 & 0.081 & 0.079 & 0.074 & 0.066 & 0.059 & 0.052 & 0.046 & 0.038 & 0.031 \\
\hline $\mathrm{A} 2$ & 0.543 & 0.473 & 0.366 & 0.289 & 0.228 & 0.181 & 0.144 & 0.116 & 0.095 & 0.078 & 0.060 & 0.047 \\
\hline B2 & 0.708 & 0.623 & 0.450 & 0.334 & 0.252 & 0.193 & 0.150 & 0.119 & 0.095 & 0.078 & 0.060 & 0.047 \\
\hline $\mathrm{C} 2$ & 0.687 & 0.614 & 0.464 & 0.343 & 0.255 & 0.192 & 0.148 & 0.117 & 0.093 & 0.077 & 0.058 & 0.046 \\
\hline $\mathrm{D} 2$ & 0.677 & 0.591 & 0.433 & 0.318 & 0.236 & 0.179 & 0.138 & 0.109 & 0.088 & 0.072 & 0.055 & 0.043 \\
\hline E2 & 0.663 & 0.548 & 0.366 & 0.264 & 0.199 & 0.154 & 0.121 & 0.097 & 0.079 & 0.066 & 0.051 & 0.040 \\
\hline F2 & 0.600 & 0.425 & 0.255 & 0.188 & 0.149 & 0.121 & 0.099 & 0.082 & 0.069 & 0.057 & 0.046 & 0.037 \\
\hline G2 & 0.136 & 0.129 & 0.117 & 0.108 & 0.098 & 0.086 & 0.076 & 0.065 & 0.057 & 0.049 & 0.040 & 0.033 \\
\hline A3 & 0.567 & 0.532 & 0.431 & 0.334 & 0.257 & 0.199 & 0.155 & 0.123 & 0.099 & 0.081 & 0.062 & 0.048 \\
\hline B3 & 0.735 & 0.696 & 0.530 & 0.387 & 0.284 & 0.213 & 0.162 & 0.127 & 0.100 & 0.082 & 0.062 & 0.048 \\
\hline $\mathrm{C} 3$ & 0.711 & 0.687 & 0.547 & 0.399 & 0.288 & 0.212 & 0.161 & 0.124 & 0.099 & 0.080 & 0.060 & 0.047 \\
\hline D3 & 0.699 & 0.659 & 0.512 & 0.370 & 0.267 & 0.197 & 0.150 & 0.117 & 0.093 & 0.076 & 0.057 & 0.045 \\
\hline E3 & 0.683 & 0.608 & 0.433 & 0.308 & 0.225 & 0.170 & 0.131 & 0.103 & 0.083 & 0.069 & 0.053 & 0.041 \\
\hline F3 & 0.614 & 0.467 & 0.301 & 0.220 & 0.170 & 0.134 & 0.107 & 0.087 & 0.072 & 0.061 & 0.047 & 0.038 \\
\hline G3 & 0.134 & 0.140 & 0.138 & 0.126 & 0.111 & 0.095 & 0.081 & 0.069 & 0.059 & 0.052 & 0.041 & 0.034 \\
\hline A4 & 0.571 & 0.543 & 0.450 & 0.349 & 0.266 & 0.204 & 0.159 & 0.126 & 0.101 & 0.083 & 0.063 & 0.049 \\
\hline B4 & 0.739 & 0.709 & 0.553 & 0.406 & 0.296 & 0.220 & 0.166 & 0.129 & 0.103 & 0.083 & 0.062 & 0.048 \\
\hline $\mathrm{C} 4$ & 0.714 & 0.700 & 0.571 & 0.417 & 0.300 & 0.219 & 0.165 & 0.127 & 0.100 & 0.081 & 0.061 & 0.047 \\
\hline D4 & 0.701 & 0.670 & 0.535 & 0.388 & 0.279 & 0.204 & 0.153 & 0.119 & 0.094 & 0.076 & 0.057 & 0.045 \\
\hline E4 & 0.684 & 0.618 & 0.453 & 0.322 & 0.235 & 0.175 & 0.135 & 0.106 & 0.085 & 0.070 & 0.054 & 0.042 \\
\hline F4 & 0.614 & 0.473 & 0.314 & 0.231 & 0.177 & 0.138 & 0.110 & 0.089 & 0.073 & 0.062 & 0.048 & 0.038 \\
\hline G4 & 0.134 & 0.141 & 0.144 & 0.132 & 0.116 & 0.098 & 0.084 & 0.071 & 0.060 & 0.052 & 0.042 & 0.035 \\
\hline
\end{tabular}




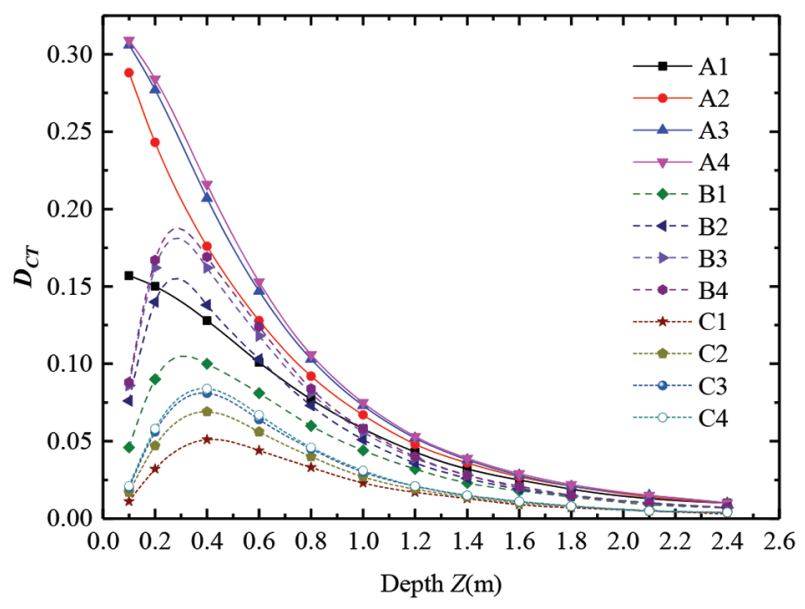

Figure 7. $D_{C T}$ versus $z$ curves at different calculation points

compression stress; whereas, in the slope direction $(X)$, the maximum and minimum values of $D_{C T}$ are on the border $(X=0)$ and centerline $(X=0.45 \mathrm{~m})$ of the loading area, respectively, which is contrary to the distribution of $D_{C N}$. Consequently, the superimposed maximum $D_{C}$ values appear in the upper part of the loading area. Figure 8 presents the $3 \mathrm{D}$ distribution surface diagram of $D_{C}$ at four representative depths $(z=0.2 \mathrm{~m}, 0.8 \mathrm{~m}, 1.6 \mathrm{~m}$ and $2.4 \mathrm{~m})$. When $z$ is small, the distribution of $D_{C}$ is as Figure $8(\mathrm{a}) ; D_{C}$ first increases with a large rate near the lower border $(G)$, then gradually increases with a small rate until reach a peak value in the upper part, and finally decreases slightly at the upper border of the loading area, displaying in an "abdominal drum" pattern. However, $D_{C}$ gradually decreases and transits to a relatively uniform "flat abdomen" distribution pattern with increasing depth. In addition, the maximum $D_{C}$ values at different depths are on
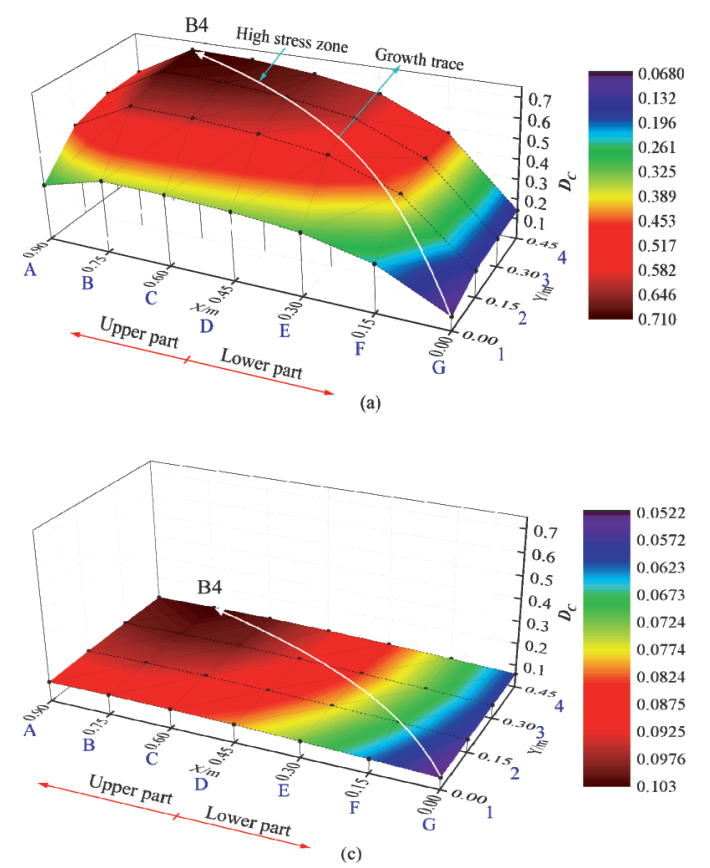

the centerline $(Y=0.45 \mathrm{~m})$ along the slope direction $(X)$ but the exact position varies with increasing depth (approximately to the path of $\mathrm{B} 4 \rightarrow \mathrm{C} 4 \rightarrow \mathrm{B} 4 \rightarrow \mathrm{A} 4$ as illustrated in Figure 8$)$. The value ranges of $D_{C}$ are $[0.068,0.71]$, $[0.079,0.3],[0.052,0.103]$ and $[0.031,0.049]$ at the depths of $0.2 \mathrm{~m}, 0.8 \mathrm{~m}, 1.6 \mathrm{~m}$ and $2.4 \mathrm{~m}$, respectively. The maximum and minimum values in the range exhibit an order of magnitude difference at the shallow depth; however, the value range becomes narrow and the distribution of $D_{C}$ gradually tends to be uniform as the depth increases. The white arrow lines in Figure 8 represent the increase potential traces of $D_{C}$; they generally point from the lower left corner to the upper middle part of the loading area.

\subsection{Additional stress in the external regions of a LPP}

The prestress subjected to a LPP is continuously diffused to the external regions outside the LPP. The regions with relatively large additional stress, i.e., zone A $(Y=0.45 \mathrm{~m})$ in the slope direction and zone $\mathrm{B}(X=0.75 \mathrm{~m})$ in the longitudinal direction (see Figure 9), are selected to analyze the effective diffusion range of the additional stress in the external regions.

\subsubsection{Distribution of $D_{C}$ in zone $\mathrm{A}(Y=0.45 \mathrm{~m})$}

The relation curves of $D_{C}$ versus $z$ at various external distances $\left(L_{x}\right)$ are shown in Figure 10. $D_{C}$ first increases to a maximum value and then gradually decreases with increasing depth, presenting a peak point on each relation curve. The depth of the peak point increases with increasing $L_{x}$, indicating that the prestress is gradually diffused outward with increasing depth. Figure 11 presents the relation curves of $D_{C}$ versus $L_{x}$ at different depths. The $D_{C}$ values in the shallow regions rapidly attenuate to stable values with increasing $L_{x}$, while the $D_{C}$ values in
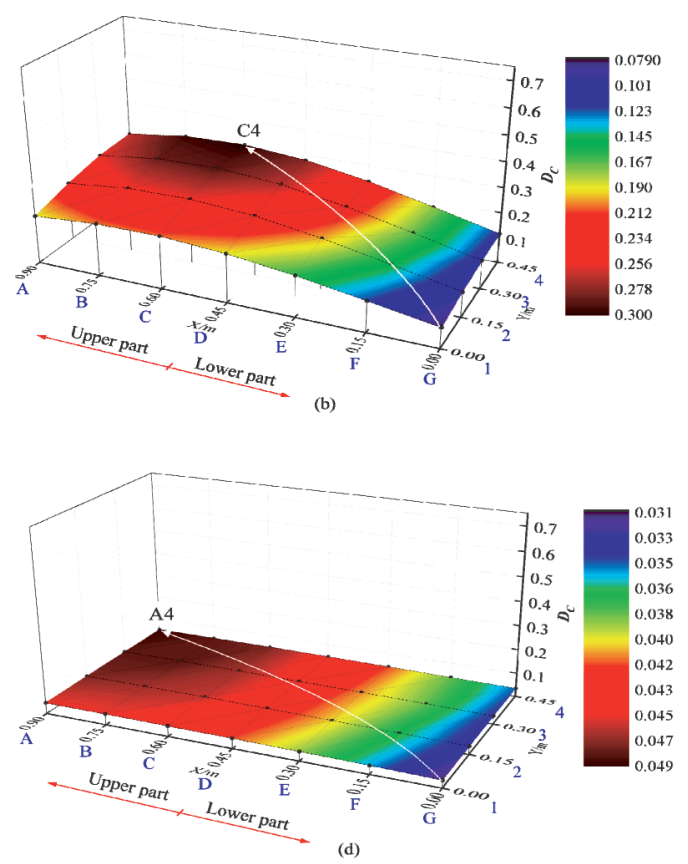

Figure 8. Diffusion coefficient distribution contours at different depths: (a) $z=0.2 \mathrm{~m}$; (b) $z=0.8 \mathrm{~m}$; (c) $z=1.6 \mathrm{~m}$; (d) $z=2.4 \mathrm{~m}$ 


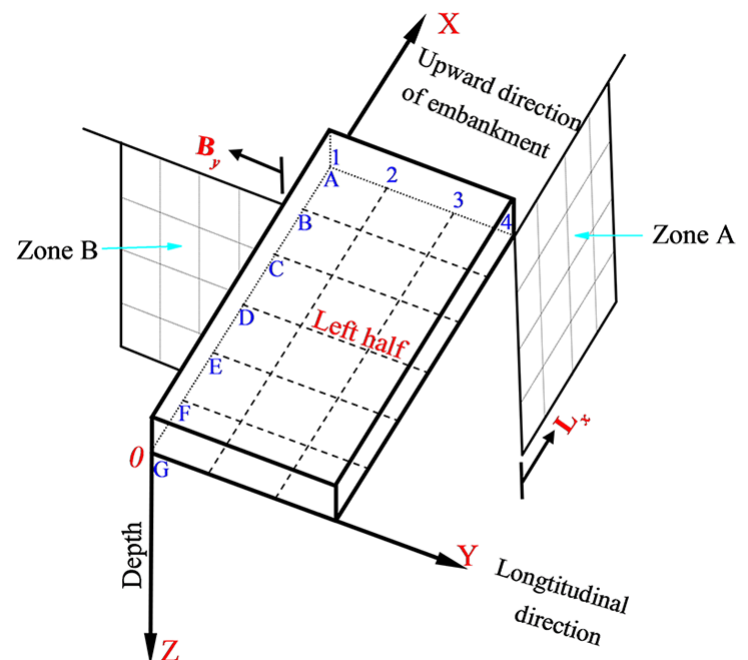

Figure 9. Calculation regions outside the plate

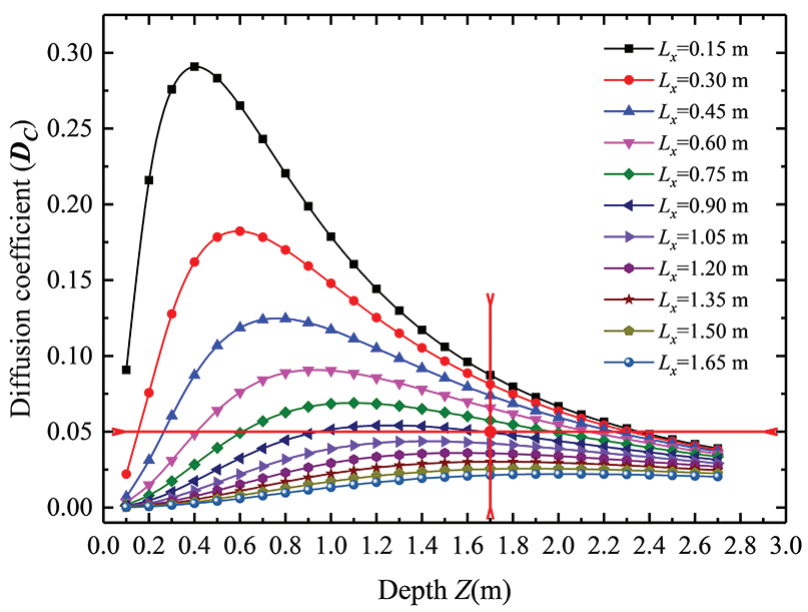

Figure 10. $D_{C}$ versus $z$ curves at different $L_{x}$ values

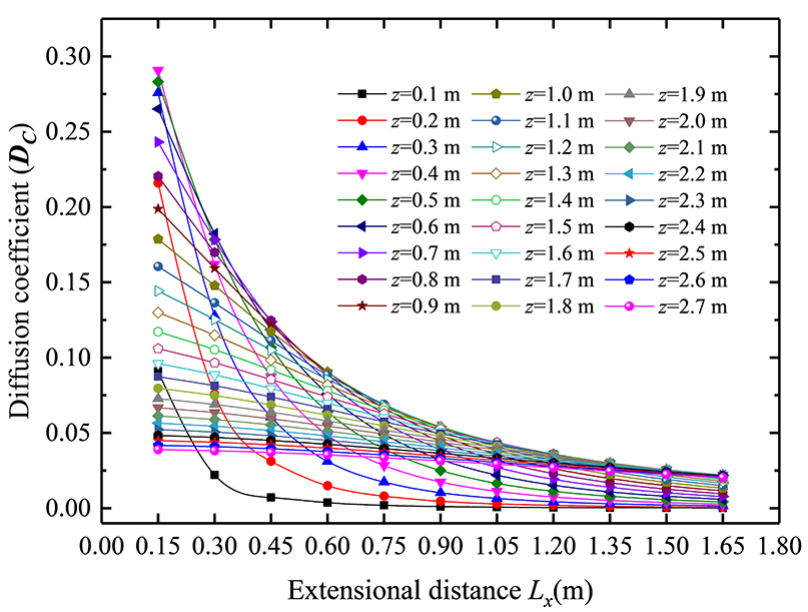

Figure 11. $D_{C}$ versus $L_{x}$ curves at different $z$ values

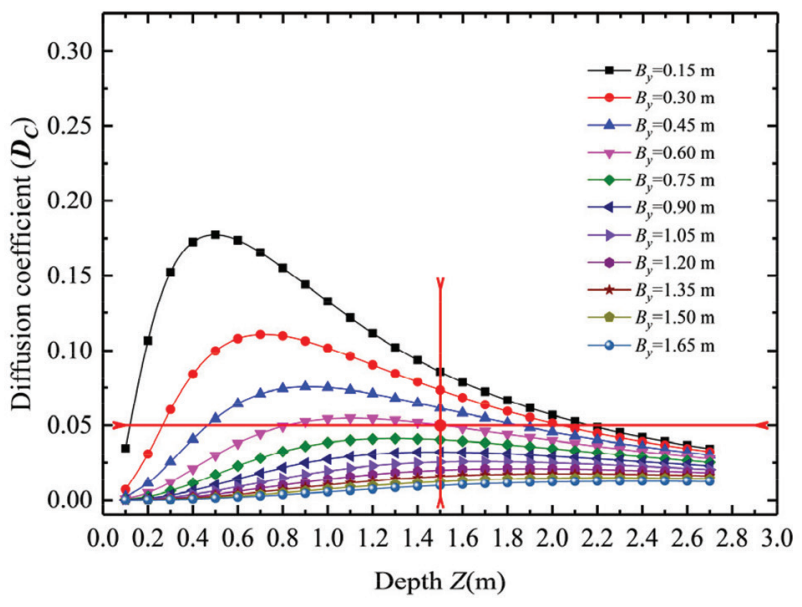

Figure 12. $D_{C}$ versus $z$ curves at different $B_{y}$ values

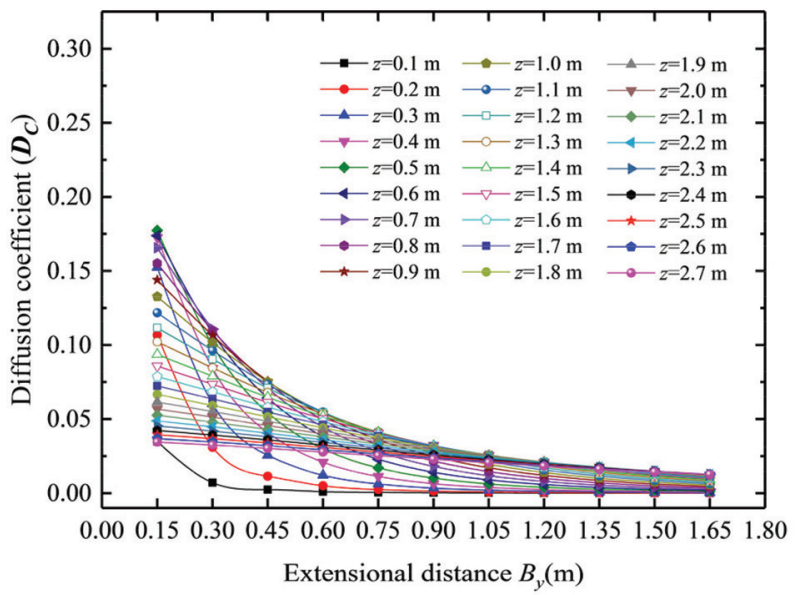

Figure 13. $D_{C}$ versus $B_{y}$ curves at different $z$ values

deep regions gradually attenuate with a small attenuation rate. Moreover, the $D_{C}$ values at the lower border of the loading area are small (less than 0.14 , see Table 3 ) because of the tension stress induced by the tangential pressure, hence the diffusion effects in the external region beyond the lower border may be negligible and are not further discussed in the present study. In case taking $D_{C}=0.05$ as a standard, the effective diffusion depth and distance in zone A can be approximately estimated as $1.7 \mathrm{~m}$ and $0.9 \mathrm{~m}$ (as shown by the intersection point of the red lines in Figure 10), respectively.

\subsubsection{Distribution of $D_{C}$ in zone B $(X=0.75 \mathrm{~m})$}

Figures 12 and 13 display the distribution curves of $D_{C}$ of zone $\mathrm{B}$ with respects to the depth $z$ and external distance $B_{y}$, respectively. The maximum $D_{C}$ approximates to 0.18 which is approximately $60 \%$ of the maximum value in zone A. There is also a peak point on each $D_{C}$ versus $z$ curve, as shown in Figure 12, and the position of the peak point similarly varies as that in the zone A. When taking $D_{C}=0.05$ as a standard, the effective diffusion depth and distance in zone B can be approximately estimated as $1.5 \mathrm{~m}$ and $0.6 \mathrm{~m}$, respectively. 


\section{Finite element analyses}

\subsection{Finite element model}

The 3D finite element model of a half PE was constructed using the ABAQUS code (Version 6.14). The analyzed embankment has a height of $8.0 \mathrm{~m}$, a half width of $4.05 \mathrm{~m}$, a slope ratio of $1: 1$ and a length of $20.0 \mathrm{~m}$. The bottom boundary was $18.0 \mathrm{~m}$ below the embankment top surface while the left boundary was $10.0 \mathrm{~m}$ away from the embankment toe, as illustrated in Figure 14. The lateral pressure plate has a plane dimension of $0.9 \mathrm{~m} \times 0.9 \mathrm{~m}$. The initial stress field approaching the embankment shoulder approximates to a zero stress state; hence local shear failure readily occurs when a pressure is applied close to the embankment shoulder edge. Therefore, it is recommend not to apply prestress near the embankment shoulder edge. The solutions of Boussinesq (1885) and Cerruti (1882) were derived based on an elastic semi-infinite space; however, existing researches (Lv \& Wang, 2004; Chen, Zhao, Wang, Jiang, \& Bian, 2013; R. P. Chen, J. M. Chen, \& Wang, 2014) and multinational design codes (German Railway Standard Rail 836, 2008; The Professional Standards Compilation Group of People's Republic of China, 2014) have demonstrated that the solutions of Boussinesq (1885) can accurately evaluate the additional stress induced by the track structures and running trains when the net spacing between the loading boundary and the embankment shoulder line reaches a certain value. Figure 10 displays that the $D_{C}$ values beyond external distances greater than $0.9 \mathrm{~m}$ (i.e., $L_{x}>0.9 \mathrm{~m}$ ) are relatively small (less than the lower control limit of $D_{C}=0.05$ ), hence a proper value of this net spacing is preliminarily judged to approximate to one time of the LPP width $(0.9 \mathrm{~m})$, which is further illustrated in Section 4.2.

The embankment soil is assumed as a weightless elastic medium with a Young's modulus of $150 \mathrm{MPa}$ and a Poisson's ratio of 0.27 (i.e., Elastic constitutive model). It needs to be mentioned that the absolute values of the involved soil parameters may have significant effects on the embankment deformation, but the effects on the distribu-

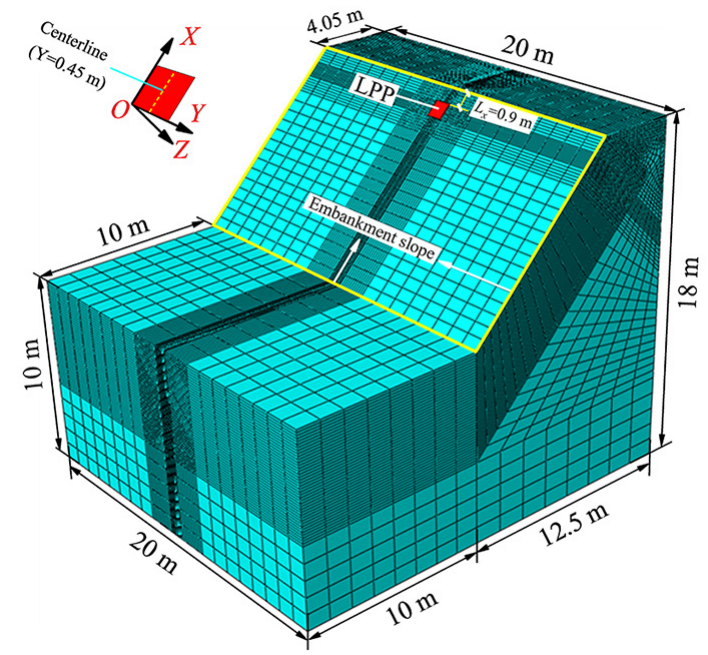

Figure 14. Numerical model of the prestressed embankment

tions of the additional stress are negligible. The horizontal displacement of the left, right, front and back boundaries was fixed but the vertical movement was allowed. While, at the bottom both the vertical and horizontal displacements were fixed. According to the symmetry, only a half of the embankment was analyzed. The detailed mesh of the FEM model is shown in Figure 14. The applied horizontal pressure is $P=100 \mathrm{kPa}$, and the net spacing between the loading boundary and the embankment shoulder line is $0.9 \mathrm{~m}$ (one time of the side length of the LPP). The local regions adjacent to the loading area are meshed so that the nodes are one-to-one correspondent to the calculation points in Section 2, as displayed in Figure 15.

\subsection{Validity and applicability of the theoretical solutions}

The $D_{C}\left(D_{C}=S 33 / P=S 33 / 100\right.$, where $S 33$ is the additional stress in the $Z$ direction obtained from the FEA) versus $z$ curves below the LPP bottom and external zones A and $\mathrm{B}$ obtained from FEA are compared with those analyzed
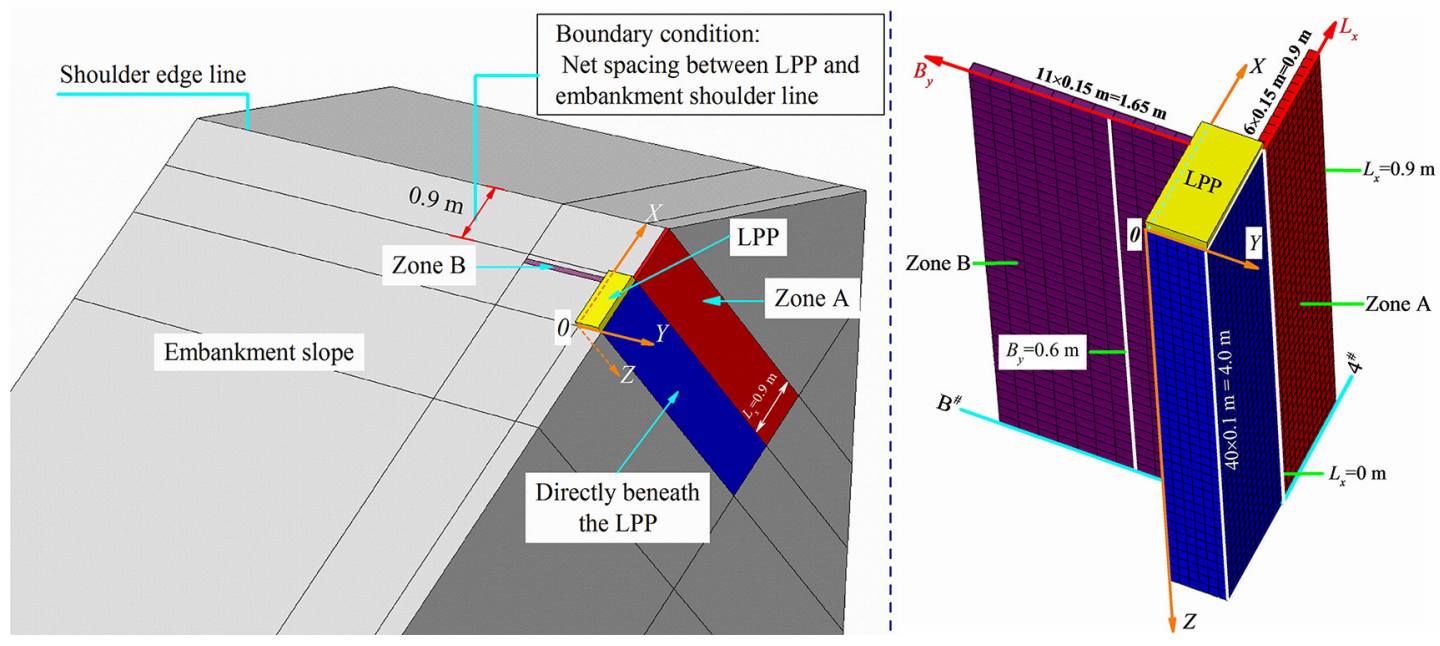

Figure 15. Net spacing between LPP and embankment shoulder edge line 
using the theoretical solutions in Figures 16, 17 and 18, respectively. The $D_{C}$ values within $0.3 \mathrm{~m}$ below the plate bottom from FEA are a little bit different from those obtained from the theoretical solutions, as displayed in Figure 16. The main reason is that the basic theory of FEA converts the surface pressure to concentration forces acting on the nodes of the finite element mesh, hence the FEA stresses are different from the theoretical solutions near the loading boundary, i.e., obeying the Saint Venant's Principle. Except this inevitable difference, the $D_{C}$ versus $z$ curves extracted from the FEA agree well with those analyzed using the theoretical solutions, including the curves corresponding to the line at the embankment shoulder edge/ boundary (see the curves with respect to $L_{x}=0.9 \mathrm{~m}$ in Figure 17), which verifies the validity and applicability of the theoretical solutions. Hence, the solutions of Boussinesq (1885) and Cerruti (1882) derived based on an elastic semi-infinite space are available to calculate the prestress in a PE, provided the net spacing between the LPP and the embankment shoulder line/boundary is greater than one time of the width of the LPP (i.e., $0.9 \mathrm{~m}$ ). Moreover, it is noteworthy that the mesh of the PE near the LPP has remarkable effects on the FEA results, thus a finer mesh can improve the accuracy of the numerical simulations.

The additional stress contour beneath the plate bottom is shown in Figure 19. The stress contour depicts a "raised abdomen" pattern in the shallow depth but gradually var-

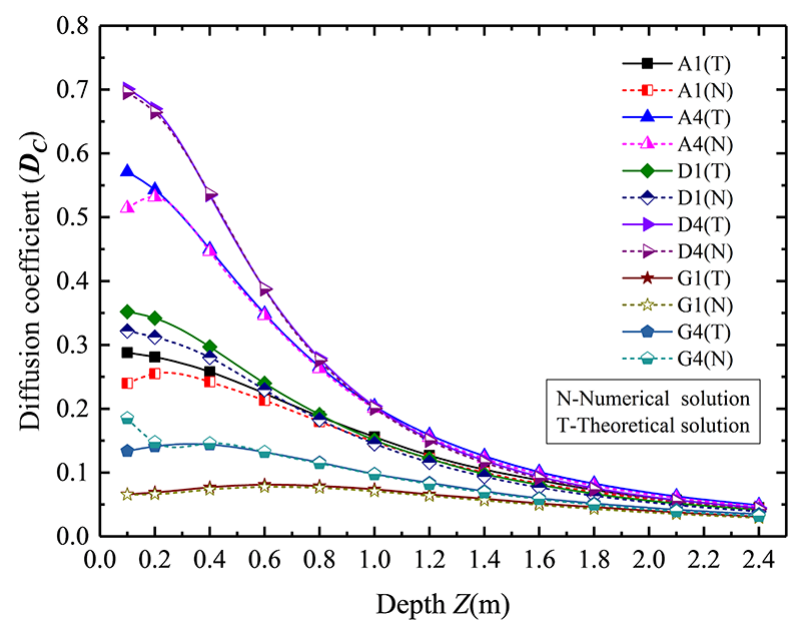

Figure 16. $D_{C}$ versus $z$ relation curves directly beneath the LPP

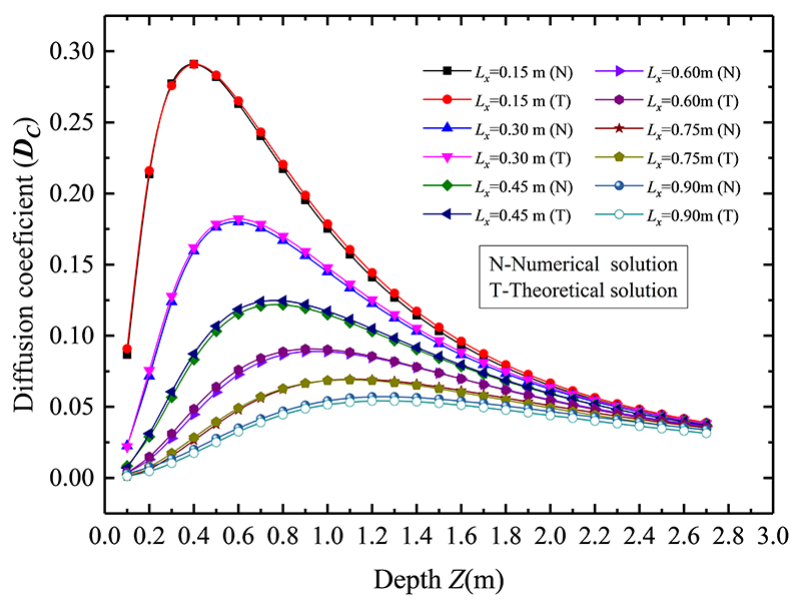

Figure 17. $D_{C}$ versus $z$ relation curves in region $\mathrm{A}$

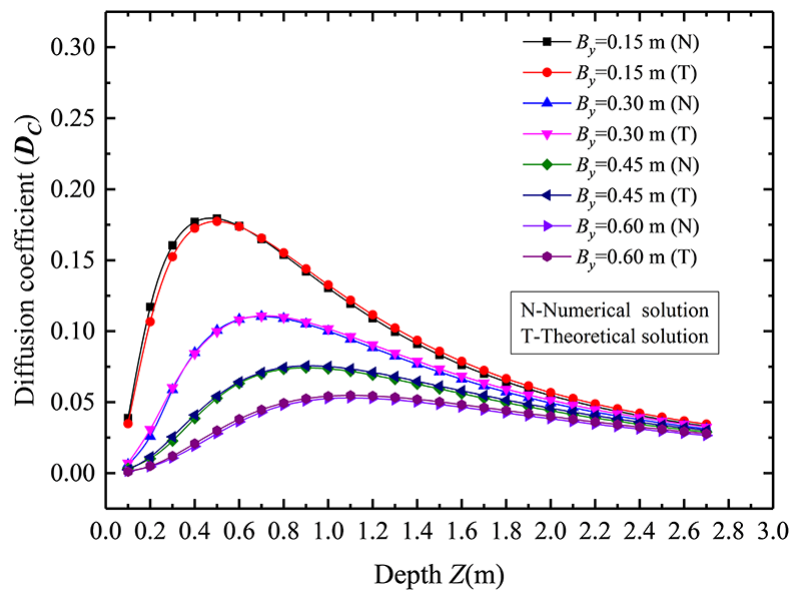

Figure 18. $D_{C}$ versus $z$ relation curves at region $\mathrm{B}$

ies to a relatively uniform "flat abdomen" pattern with increasing depth, which again agrees well with the theoretical solutions.

\subsection{Additional stress contour and diffusion angles of peak stresses}

The additional stress $\left(\sigma_{z}\right)$ contour in the $Z$ direction is displayed in Figure 20. Generally, the additional stress forms a series of stress bubbles and gradually transfers to

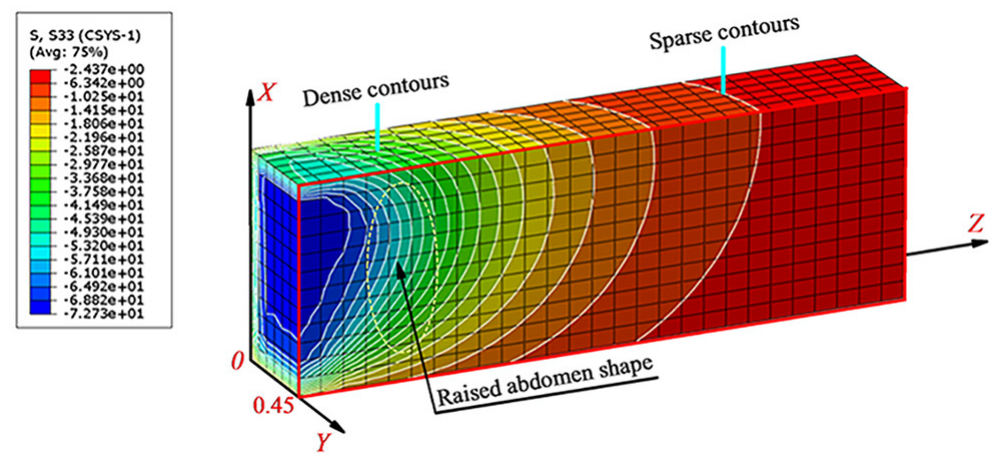

Figure 19. Additional stress contour (S33) beneath the plate bottom 


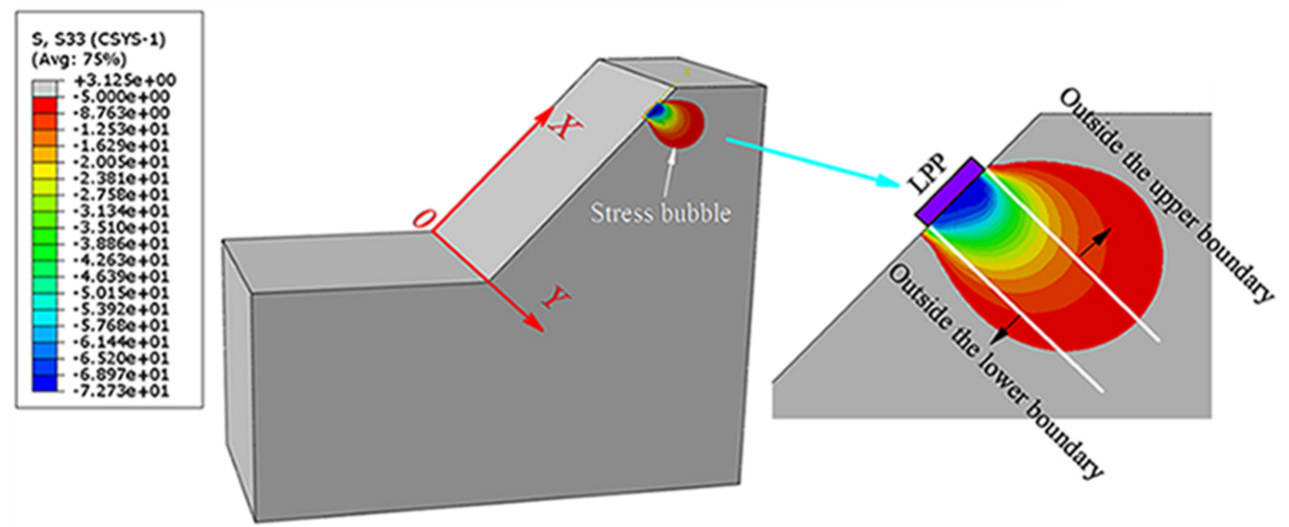

Figure 20. Additional stress contour subjected to one lateral pressure plate

the core zones that mainly bear the train loads (e.g., the zones directly below sleepers). The diffusion range of the additional stress beyond the upper border of the loading area is much greater than that beyond the lower border. The main reason is that the tangential pressure component induces compression stress in the regions beyond the upper border of the plate but results in tension stress in the regions beyond the lower border of the plate, which forces the prestress readily propagates in the region beyond the upper border.

The stress contour lines in the external regions $\mathrm{A}$ and B are presented in Figures 21(a) and 21(b), respectively. In region $\mathrm{A}$, the contour lines are asymmetric to the centerline of the plate because of the effects of the tangential pressure component. In the $Z$ direction, plotting a tangential line to each of the contour lines, the diffusion angles of peak stress ( $\alpha$ and $\beta$ ) in the external regions $A$ and $B$ can be evaluated as the intersections angle between the horizontal line and the line connecting the tangent points.

The position coordinates of the tangent points $\left(\left(L_{x}\right.\right.$, $\left.Z_{p A}\right)$ and $\left.\left(B_{y}, Z_{p B}\right)\right)$ are extracted, and the $L_{x}$ versus $Z_{p A}$ and $B_{y}$ versus $Z_{p B}$ relationships are presented in Figures 22(a) and 22(b), respectively, where $Z_{p A}$ and $Z_{p B}$ are the depth of the peak $\sigma_{z}$ at a given external distance in zones A and B, respectively. $L_{x}$ and $B_{y}$ approximately linear increase with increasing $Z_{p A}$ and $Z_{p B}$, respectively, implying the pre-

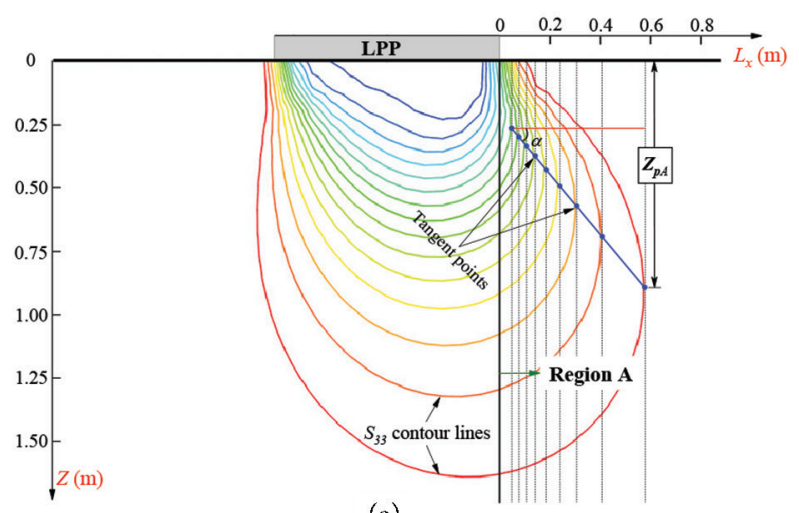

stress gradually diffuses outward as the depth increases. The angles between the regression lines and horizontal line in Figures 22(a) and 22(b) approximate to $50^{\circ}$ and $58^{\circ}$, respectively. Consequently, the additional stress is transferred to the core zones that mainly bear the train loads with peak stress diffusion angles of $50^{\circ}$ and $58^{\circ}$ in external regions $A$ and $B$, respectively. It should be noted that the peak stress diffusion angles are case dependent and are mainly related to the LPP size and the embankment slope ratio; further studies on this issue are required.

\section{Design spacing of LPPs}

The spacing of the lateral pressure plates is a key design parameter of a prestressed embankment. The LPPs diffuse the prestress to the interior of the embankment, and the superposition of the additional stresses subjected to multiLPPs can effectively enlarge the reinforcement zone of a PE. As shown in Figure 23, the net spacing of the LPP along the slope and longitudinal directions of the $\mathrm{PE}$ are $m$ and $n$, respectively. Hence, the green area without the action of a LPP is the weak reinforcement region. Preliminary analyses combining the theoretical solutions and FEAs displayed that the additional stresses in the weak region are mainly provided by the adjacent four LPPs and the weakest reinforcement points at different depths are

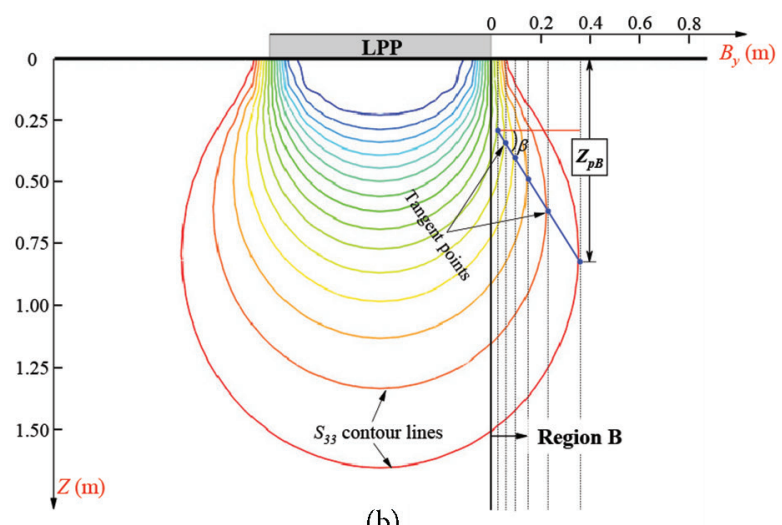

(b)

Figure 21. Additional stress contour lines in external regions: (a) region A; (b) region B 


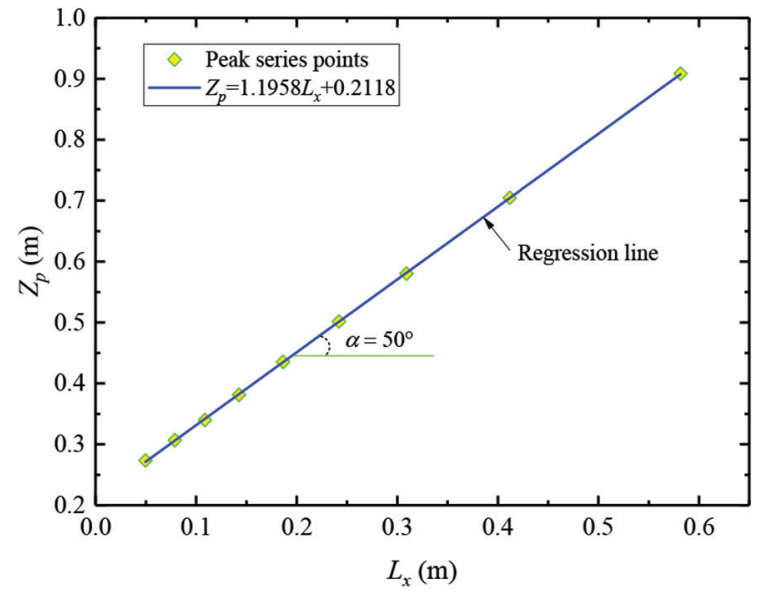

(a)

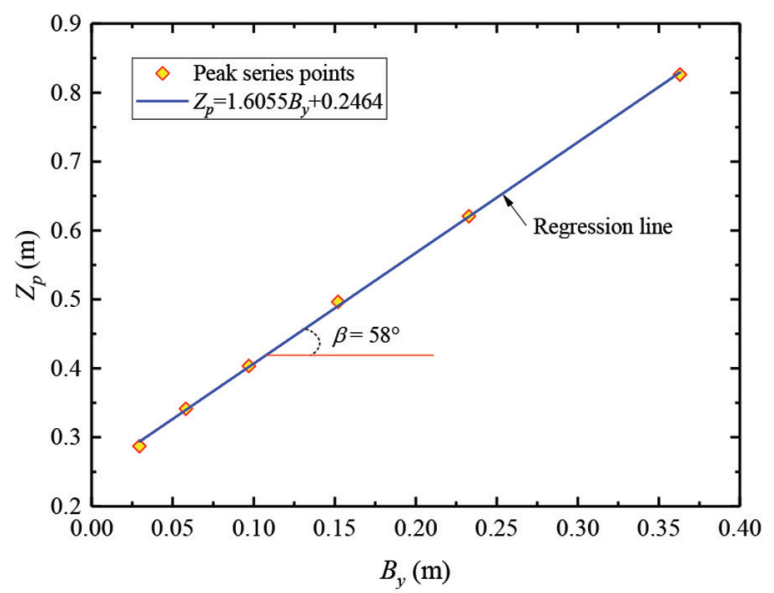

(b)

Figure 22. Peak diffusion angles in the external regions: (a) region A; (b) region B

locatedaround the projection (in the $Z$ direction) of the center point $\left(P_{C}\right)$ of the weak region (see Figure 23 ).

In the present study, a $D_{C}$ value of 0.05 is set as the lower limit to evaluate the effective diffusion range of a LPP, and the average effective diffusion depth in the external regions $\mathrm{A}$ and $\mathrm{B}$ approximates to $1.6 \mathrm{~m}$ according to the characteristics of the $D_{C}$ versus $z$ curves presented in section 4.2. Under the action of multi-LPPs, the total additional stress at any point in the weak region is mainly superimposed from the adjacent four plates. However, the additional stresses in this weak region subjected to the upper two LPPs (LPP Nos. 1 and 2 in Figure 23) are small, hence a total $D_{C}$ value of 0.1 is adopted as a lower limit to control the design of the LPP spacing. A series of theoretical analyses were conducted to investigate the correlation between the spacing parameters $m$ and $n$. Totally, 252 cases were analyzed, provided $m$ and $n$ varied with an interval of $0.1 \mathrm{~m}$ in the ranges of $0.1-1.2 \mathrm{~m}$ and $0.4-2.4 \mathrm{~m}$, respectively. The analyzed $D_{C}$ values at the effective diffusion depth of $1.6 \mathrm{~m}$ directly below the center point $P_{\mathrm{C}}$ are plotted with respect to $n$ for different $m$ values, as presented in Figure 24. It is observed that $D_{C}$ decreases with increasing spacing parameters $m$ and $n$. The relationship

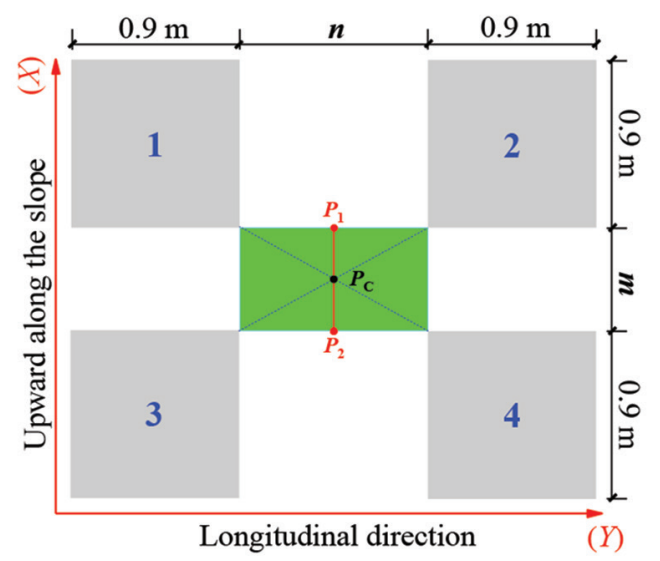

Figure 23. Spacing parameters of the lateral pressure plates between $m$ and $n$ in the condition of maintaining a minimum $D_{C}$ value approximating to 0.1 was obtained by analyzing the coordinates of the intersection points between $D_{C}$ versus $n$ curves and the line of $D_{C}=0.1$ (see Figure 24). The analyzed relationship between $m$ and $n$ is illustrated in Figure 25. It clearly shows that there is a negative correlation between the spacing parameters $m$ and $n$. In addition, the values of $m$ and $n$ can be selected as $1.1 \mathrm{~m}$ to maintain a uniform plate layout in the slope $(X)$ and longitudinal $(Y)$ directions, as illustrated in Figure 25. Figure 26 displays the additional stress contour (S33) of the weak reinforcement region subjected to a LPP net spacing of $1.1 \mathrm{~m}$. When converting $S 33$ to $D_{C}$ (i.e., $D_{C}=S 33 / P$ ), it is observed that the minimum $D_{C}$ is located around the center point $\left(P_{C}\right)$ of the weak region with a value of 0.1034 , as shown in Figure 26; while the maximum $D_{C}$ is located at the upper left corner of the weak region with a value of 0.1191 . The minimum and maximum $D_{C}$ values are very close and are greater than the lower control limit of 0.1 . Consequently, a continuous, effective and relatively uniform reinforcement zone with a $D_{C}$ value greater than 0.1 is formed at the effective diffusion depth of $1.6 \mathrm{~m}$, provided the net spacing of the plates is $1.1 \mathrm{~m}$. It is worth noting that the design spacing of the LPPs is case dependent, and further studies on the design spacing of LPPs under different LPP sizes and embankment slope ratios are desirable.

\section{Reinforcement mechanism of PE}

Two different zones can be identified in a PE, i.e., a prestressing protective layer and core zones that mainly bear the stresses transferred from the moving trains, as shown in Figure 27. The prestress in the protective layer presents an extremely non-uniform distribution and rapidly attenuates with increasing depth. Whereas, under the superposition effects of adjacent LPPs, the prestress on the boundary of the core zones still remains around a desired value, and the $D_{C}$ relatively uniformly distributes with a slow attenuation rate, thus providing an effective 


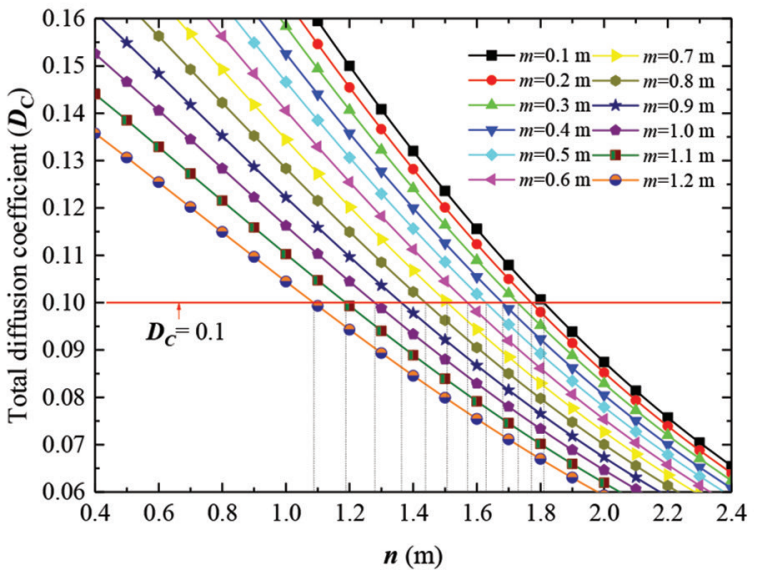

Figure 24. $D_{C}$ versus $n$ relation curves with different $m$ values

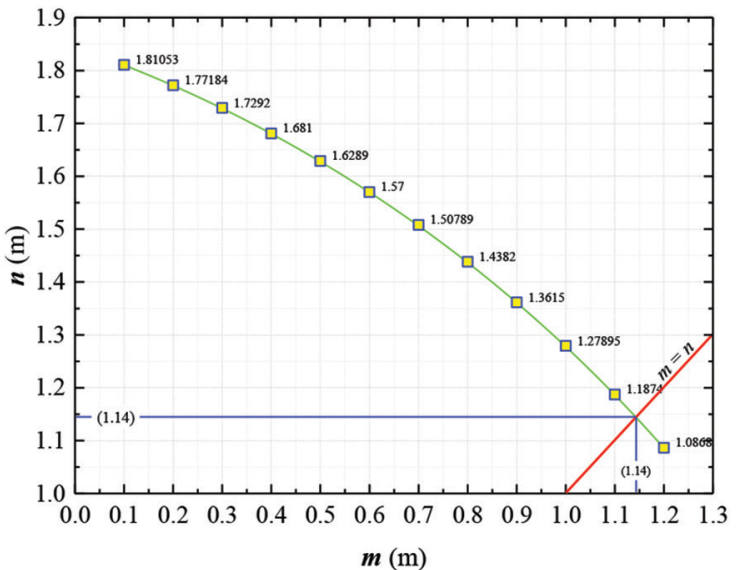

Figure 25. $m$ versus $n$ relation curve at $z=1.6 \mathrm{~m}$
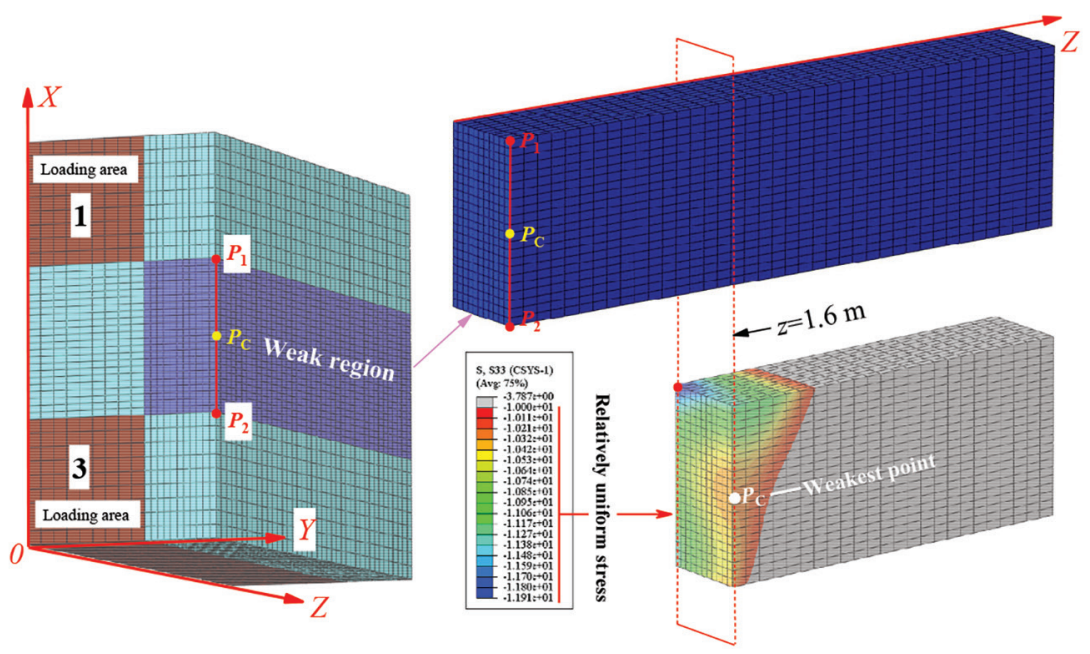

Figure 26. Additional stress subjected to multiple LPPs with net spacing of $1.1 \mathrm{~m}$

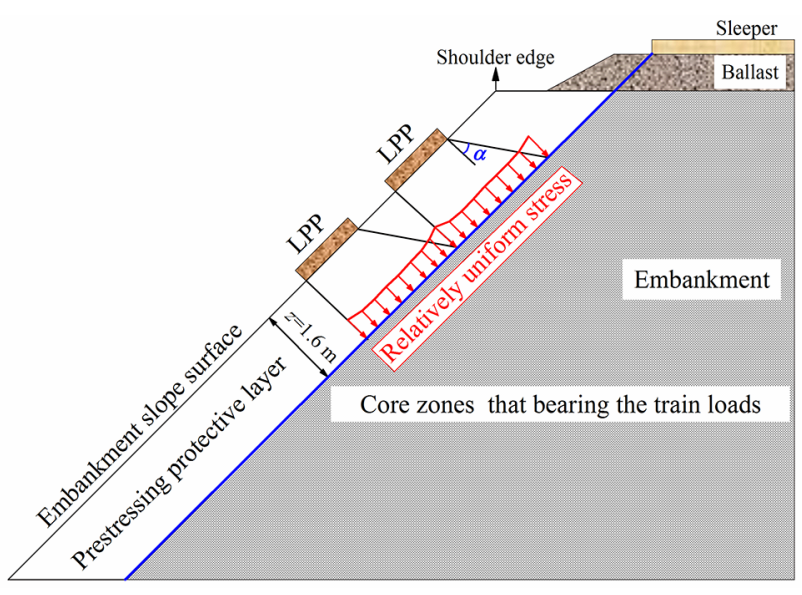

Figure 27. Reinforced mechanism of a PE additional stress for the core zones. Besides, the reinforcement zone above the core zone can function as an effective protective layer of a PE.

\section{Conclusions}

The prestressed reinforcement device (PRD) consisting of two lateral pressure plates (LPPs) and a reinforcement bar is a new structure for strengthening soil embankment and can effectively prevent/remedy railway embankment problems. A mechanical model for a prestressed embankment (PE) was established, and theoretical solutions were derived to calculate the additional stress/prestress in a PE induced by a PRD. The validity and applicability of the theoretical solutions and the diffusion characteristics of the prestress in a PE with a LPP having width of $0.9 \mathrm{~m}$ and a slope ratio of 1:1 as a sample case were analyzed using the theoretical solutions and a 3D finite element analysis. Finally, an analysis technique is recommended to design the required LPPs spacing. The main conclusions that can be drawn are as follows:

1. The FEA indicates that the theoretical solutions are available to calculate the prestress in a PE, provided 
the net spacing between the LPP and the embankment shoulder is greater than one time of the LPP width. The prestress directly below a LPP presents an "abdominal drum" pattern at the shallow depth but gradually transits to a relatively uniform "flat abdomen" pattern as the depth increases.

2. The maximum prestress appears in the upper part of the loading area because the tangential pressure component along the slope direction $\left(q_{2}\right)$ induces compression stress in the upper part of the loading area but results in tension stress in the lower part. The prestress readily propagates in the upper external region of the LPP due to the effects of $q_{2}$.

3. The prestress in the external regions of LPP first increases to a maximum value and then gradually decreases with increasing depth, and it propagates to the core zones that mainly bear the train loads with certain peak stress diffusion angles. For the analyzed sample case, the diffusion angles are $50^{\circ}$ and $58^{\circ}$ in the external regions of the LPP along the slope and longitudinal directions, respectively. However, the diffusion angles are case dependent and are mainly related to the LPP size and the embankment slope ratio; further studies on this issue are required.

4. The net spacing of the LPPs along the slope direction has a negative correlation with that along the longitudinal direction of a PE when keeping the diffusion coefficient of prestress $\left(D_{C}\right)$ fixed. A continuous, effective and relatively uniform prestressing protective layer with a $D_{C}$ value greater than 0.1 can be formed on the boundary of the core zones (or the effective diffusion depth of the prestress) when the LPP spacing is properly designed. For the analyzed sample case, the proper design net spacing of the LPPs is $1.1 \mathrm{~m}$. Further studies on the design spacing of LPPs under different LPP sizes and embankment slope ratios are desirable.

\section{Acknowledgements}

This work was supported by the National Natural Science Foundation of China (Grant Nos. 51709284; 51678572; 51878666). Their financial support is gratefully acknowledged.

\section{Funding}

This work was supported by the National Natural Science Foundation of China under Grant Nos. 51709284; $51678572 ; 51878666$.

\section{Author contributions}

All authors were involved in conceiving the study, data analysis and structure of the paper. Qishu Zhang applied the elastic theory to analyze the additional stress field of the PE. Wuming Leng proposed the spacing design of LPPs. Fang Xu validated the applicability of the theoreti- cal solutions using FEA. Qi Yang and Xi Ai revised the first version of the paper. Qishu Zhang and Fang Xu wrote the paper, as well as reviewed and edited the manuscript drafts.

\section{Disclosure statement}

The authors declare that there are no conflicts of interest regarding the publication of this paper.

\section{References}

Alonso, E. E., \& Ramon, A. (2013). Massive sulfate attack to cement-treated railway embankments. Géotechnique, 63(10), 857-870. https://doi.org/10.1680/geot.SIP13.P.023

Boussinesq, J. (1885). Application des potentiels à l'étude de léquilibre et du mouvement des solides élastiques. Paris: Gauthier-Villars.

Cerruti, V. (1882). Ricerche intorno allequilibrio de corpi elastici isotropi. Atti della R. Accademia dei Lincei, Memoriae della classe di scienze fisiche, matematiche e naturali.

Chen, G., Chen, T., Chen, Y., Huang, R., \& Liu, M. (2018a). A new method of predicting the prestress variations in anchored cables with excavation unloading destruction. Engineering Geology, 241, 109-120. https://doi.org/10.1016/j.enggeo.2018.05.015

Chen, R. P., Chen, J. M., \& Wang, H. L. (2014). Recent research on the track-subgrade of high-speed railways. Journal of Zhejiang University Science A, 15(12), 1034-1038. https://doi.org/10.1631/jzus.A1400342

Chen, R. P., Zhao, X., Wang, Z., Jiang, H., \& Bian, X. (2013). Experimental study on dynamic load magnification factor for ballastless track-subgrade of high-speed railway. Journal of Rock Mechanics and Geotechnical Engineering, 5(4), 306-311. https://doi.org/10.1016/j.jrmge.2013.04.004

Chen, W. B., Yin, J. H., Feng, W. Q., Borana, L., \& Chen, R. P. (2018b). Accumulated permanent axial strain of a subgrade fill under cyclic high-speed railway loading. International Journal of Geomechanics, 18(5), 04018018.

https://doi.org/10.1061/(ASCE)gm.1943-5622.0001119

Deng, D. P., Zhao, L. H., \& Li, L. (2017). Limit-equilibrium analysis on stability of a reinforced slope with a grid beam anchored by cables. International Journal of Geomechanics, 17(9), 06017013.

https://doi.org/10.1061/(ASCE)GM.1943-5622.0000964

Dong, J., Wu, Z. H., Li, X., \& Chen, H. Y. (2018). Dynamic response and pile-soil interaction of a heavy-haul railway embankment slope reinforced by micro-piles. Computers and Geotechnics, 100, 144-157. https://doi.org/10.1016/j.compgeo.2018.04.005

Du, Z., Qin, B., \& Tian, F. (2016). Numerical analysis of the effects of rock bolts on stress redistribution around a roadway. International Journal of Mining Science and Technology, 26(6), 975-980. https://doi.org/10.1016/j.ijmst.2016.09.003

Esmaeili, M., Naderi, B., Neyestanaki, H. K., \& Khodaverdian, A. (2018). Investigating the effect of geogrid on stabilization of high railway embankments. Soils and Foundations, 58(2), 319-332. https://doi.org/10.1016/j.sandf.2018.02.005

Fuggini, C., Zangani, D., Wosniok, A., Krebber, K., \& Weigand, F. (2016). Innovative approach in the use of geotextiles for failures prevention in railway embankments. Transportation Research Procedia, 14, 1875-1883.

https://doi.org/10.1016/j.trpro.2016.05.154 
German Railway Standard Rail 836. (2008). Erdbauwerkeplanen, bauen und instandhalten (in German).

Ghayoomi, M., Suprunenko, G., \& Mirshekari, M. (2017). Cyclic triaxial test to measure strain-dependent shear modulus of unsaturated sand. International Journal of Geomechanics, 17(9), 04017043. https://doi.org/10.1061/(asce)gm.1943-5622.0000917

Guo, X., Mao, X., Ma, C., \& Huang, J. (2013). Bolt support mechanism based on elastic theory. International Journal of Mining Science and Technology, 23(4), 469-474.

https://doi.org/10.1016/j.ijmst.2013.07.002

Lackenby, J., Indraratna, B., McDowell, G., \& Christie, D. (2007). Effect of confining pressure on ballast degradation and deformation under cyclic triaxial loading. Géotechnique, 57(6), 527-536. https://doi.org/10.1680/geot.2007.57.6.527

Lenart, S., Koseki, J., Miyashita, Y., \& Sato, T. (2014). Large-scale triaxial tests of dense gravel material at low confining pressures. Soils and Foundations, 54(1), 45-55. https://doi.org/10.1016/j.sandf.2013.12.005

Leng, W. M., Nie, R. S., \& Yang, Q. (2016). A new type of prestressed embankment structure and its properties. Journal of the China Railway Society, 38(11), 111-119.

Leng, W. M., Xiao, Y. J., Nie, R. S., Zhou, W. Q., \& Liu, W. J. (2017). Investigating strength and deformation characteristics of heavy-haul railway embankment materials using largescale undrained cyclic triaxial tests. International Journal of Geomechanics, 17(9), 04017074. https://doi.org/10.1061/(ASCE)gm.1943-5622.0000956

Leshchinsky, B., \& Ling, H. (2013). Effects of geocell confinement on strength and deformation behavior of gravel. Journal of Geotechnical and Geoenvironmental Engineering, 139(2), 340352. https://doi.org/10.1061/(ASCE)GT.1943-5606.0000757

Li, D. (2018). 25 years of heavy axle load railway subgrade research at the facility for accelerated service testing (FAST). Transportation Geotechnics, 17, 51-60. https://doi.org/10.1016/j.trgeo.2018.09.003

Li, J., Chen, S. X., \& Jiang, L. F. (2016). Test study on the influences of dynamic stress and load history to the dynamic properties of the remolded red clay. Earth Sciences Research Journal, 20(4), G1-G8. https://doi.org/10.15446/esrj.v20n4.54400

Li, J., Chen, S., \& Jiang, L. (2015). Dynamic strength and accumulated plastic strain development laws and models of the remolded red clay under long-term cyclic loads: laboratory test results. Polish Maritime Research, 22(s1), 89-94. https://doi.org/10.1515/pomr-2015-0038

Li, J., Cheng, S. X., Jiang, L. F., \& Xiong, S. D. (2014). Experimental study on influence of stress history on dynamic properties of remolded red clay. Chinese Journal of Geotechnical Engineering, 39(9), 1657-1665.

Lin, B., Zhang, F., Feng, D., Tang, K., \& Feng, X. (2017). Accumulative plastic strain of thawed saturated clay under longterm cyclic loading. Engineering Geology, 231, 230-237. https://doi.org/10.1016/j.enggeo.2017.09.028
Lin, J., Shi, Y., Sun, Z. Y., Wang, Z. S., \& Cai, J. F. (2016). Large scale model test on the distribution characteristics of the prestressed field of end-anchored bolts. Chinese Journal of Rock Mechanics and Engineering, 35(11), 2237-2247.

Lv, W. T., \& Wang, Y. H. (2004). Dynamic stress analysis of subgrade-bridge transition section of Qin-Shen railway. Chinese Journal of Rock Mechanics and Engineering, 23(3), 500-504.

Ozhan, H. O., \& Guler, E. (2017). Critical tendon bond length for prestressed ground anchors in pullout performance tests conducted in sand. International Journal of Civil Engineering, 16(10), 1329-1340.

https://doi.org/10.1007/s40999-017-0261-0

Sabermahani, M., Esmaeili, M., \& Neyestanaki, H. K. (2017). Effect of the grouted tied back-to-back system on the stability of railway embankments. International Journal of Physical Modelling in Geotechnics, 18(4), 1-17.

https://doi.org/10.1680/jphmg.17.00022

Sivakumar, V., Kodikara, J., O’Hagan, R., Hughes, D., Cairns, P., \& Mckinley, J. D. (2013). Effects of confining pressure and water content on performance of unsaturated compacted clay under repeated loading. Géotechnique, 63(8), 628-640. https://doi.org/10.1680/geot.10.P.103

Thakur, P. K., Vinod, J. S., \& Indraratna, B. (2013). Effect of confining pressure and frequency on the deformation of ballast. Géotechnique, 63, 786-790. https://doi.org/10.1680/geot.12.T.001

The Professional Standards Compilation Group of People's Republic of China. (2014). Code for design of high speed railway (TB 10621-2014). Beijing: China Railway Publishing House.

Wu, Y., Mao, X., Huang, J., Sun, F., \& Yao, B. (2010). Action mechanism of a mechanical end-anchorage bolt. Mining Science and Technology, 20(4), 625-628. https://doi.org/10.1016/S1674-5264(09)60256-8

Xu, H. Y., Chen, L. Z., \& Deng, J. L. (2014). Uplift tests of jet mixing anchor pile. Soils and Foundations, 54(2), 168-175. https://doi.org/10.1016/j.sandf.2014.02.008

Xu, M., Tang, Y. F., Liu, X. S., Yang, H. Q., \& Luo, B. (2018). A shaking table model test on a rock slope anchored with adaptive anchor cables. International Journal of Rock Mechanics and Mining Sciences, 112, 201-208. https://doi.org/10.1016/j.ijrmms.2018.10.021

Xue, J. L. (2014). Influence of reinforcement parameters of reinforced cement soil piles on reinforcement effect of heavy haul railway subgrade. China Railway Science, 35(6), 15-20.

Yang, J., \& Feng, Q. B. (2013). A new method for measuring subgrade settlement in high-speed railway by using a linear CCD. Measurement, 46(5), 1751-1756. https://doi.org/10.1016/j.measurement.2012.11.049

Zhang, C. L., Jiang, G. L., \& Su, L. J. (2018). Dynamic behaviour of weathered red mudstone in Sichuan (China) under triaxial cyclic loading. Journal of Mountain Science, 15(8), 1789-1806. https://doi.org/10.1007/s11629-017-4756-6 